\title{
Ogawa's nipponium and its re-assignment to rhenium
}

\author{
Yoji Hisamatsu $^{1} \cdot$ Kazuhiro Egashira ${ }^{2}$ (D) Yoshiteru Maeno $^{3}$ (D)
}

Accepted: 12 August 2021 / Published online: 18 October 2021

(c) The Author(s) 2021

\begin{abstract}
We re-examine the history of the element "nipponium" discovered by a Japanese chemist Masataka Ogawa in 1908. Since 1996 H.K. Yoshihara has made extensive research into Ogawa's work and revealed evidence that nipponium proposed for the place of the atomic number of 43 was actually rhenium (75). In this paper, we provide critical re-interpretations of the existing information and confirmed that Ogawa left indisputable evidence that nipponium was in fact rhenium. We further discuss the reasons for the existing doubts and criticism against Ogawa's discovery and Yoshihara's interpretation, and attempt to resolve them.
\end{abstract}

Keywords Nipponium · Nihonium · Rhenium · Masataka Ogawa $\cdot$ Element 43 - Thorianite

\section{Introduction}

Among the new elements given the official names in 2016, the element 113 "nihonium" (Nh) marks the first case of an element name originating from Asia (Morita et al. 2004). It is named after one of the common Japanese words for "Japan", namely "Nihon" and "Nippon". The focus of this paper is on another element named "nipponium" (Np) just about one hundred years prior to nihonium by a Japanese chemist, Masataka Ogawa (1865-1930), as a result of his studies in the laboratory of Sir William Ramsay (1852-1916) at University College London (UCL) during 1904-1906 (Ogawa 1908a, 1909). Ogawa considered this element residing between molybdenum (42) and ruthenium (44) with the atomic weight of about 100. While Ogawa was not able to report further progress in its identification, Walter Noddack, Ida Tacke, and Otto Berg reported the element 43 masurium (Ma), along with the element 75 rhenium (Re) (Noddack et al. 1925). It turned out that their report on the new element 43 was incorrect, but it was finally discovered in 1937 by nuclear reaction

Yoji Hisamatsu

y-hisamatsu@sci-museum.niihama.ehime.jp

Kazuhiro Egashira

egashira@clusterlab.jp

Yoshiteru Maeno

maeno.yoshiteru.2e@kyoto-u.ac.jp

1 Curatorial Division, Ehime Prefectural Science Museum, Ehime 792-0060, Japan

2 East Tokyo Laboratory, Genesis Research Institute, Inc., Chiba 272-0001, Japan

3 Department of Physics, Kyoto University, Kyoto 606-8502, Japan 
as an unstable element technetium (Tc) (Perrier and Segré 1937). Ogawa's nipponium had been nearly forgotten from the international community. The symbol $\mathrm{Np}$ is now assigned to the 93rd element neptunium.

What Ogawa discovered could be deduced from the resources he and his contemporaries have left. In particular, investigations by H. Kenji Yoshihara since 1996 have provided evidence from the original X-ray photographic plate in Ogawa's lab. In combination with the optical emission spectra, the mass ratios of decomposing the chlorides and sulfates into oxides, and the composition of the kinds of minerals Ogawa used to extract nipponium, as well as a number of records of communications and documents, Yoshihara concluded that what Ogawa actually discovered was rhenium.

Yoshihara's extensive investigation that identified Ogawa's nipponium as rhenium has led to a wide international recognition. However, there are still remaining criticisms and misunderstandings against this identification. We list some of the reasons:

1. Is there solid evidence that Ogawa's nipponium was actually rhenium?

2. How sure was Ogawa himself that he discovered the new element and the atomic weight corresponding to the 43rd element?

3. Is it really possible to extract nearly $100 \mathrm{mg}$ of rhenium from the thorianite mineral?

4. Why did Ogawa not report on detailed properties of nipponium after his first three papers, especially on X-ray spectroscopic evidence that became available in later years?

5. Why did Ogawa not re-assign nipponium as the element 75 himself even after the report by the Noddacks? And why did Ogawa's colleagues in Japan not report on such a reassignment even after Ogawa's death?

6. Why is the absence of rhenium in the zirconium silicate often used as evidence against Ogawa's discovery of the new element, although the silicate is contained only as a segregated impurity phase in thorianite?

In this paper, we summarize in Section "Ogawa's claimed discovery of nipponium" the main contents of Ogawa's papers including the one published only in Japanese, as well as Yoshihara's achievements. We then re-examine in Section "Ogawa's nipponium and rhenium" Yoshihara's deduction of the actual chemical reactions in Ogawa's investigation and re-assign some of the chemical products. We also present a revised assignment of the peaks in the X-ray photographic plate from those considered by Yoshihara. These critical re-examinations led us to conclude that the new element Ogawa obtained was in fact rhenium. In Section “Assessments of Ogawa's nipponium”, we discuss why Ogawa and his colleagues after all could not properly identify the new element Ogawa discovered. In Section "Conclusions" we summarize our answers to the questions listed above. We made diagrams representing the details of the chemical processes Ogawa described in his papers; they are added as Appendix A. We also added as Appendix B the translation of one of Yoshihara's papers originally published only in Japanese (Yoshihara 2015).

\section{Ogawa's claimed discovery of nipponium}

\section{Ogawa's work}

Masataka Ogawa was born in Edo (the old name of Tokyo until 1868) in 1865 as the son of a samurai family (warrior class). This was a few years before the Meiji Restoration, 
which revolutionized Japanese society toward Western culture. He grew up in Matsuyama in Ehime Prefecture, the hometown of his father. At the age of sixteen, he moved to Tokyo to receive newly Westernized education. He graduated from the Imperial University (the University of Tokyo today) in 1889 with a bachelor's degree in chemistry, and entered its graduate school to be a chemist under the supervision of Edward Divers (1837-1912). For financial reasons, however, he could not continue his graduate study and took up a position as a junior high school teacher in Shizuoka. He did not give up his strong desire to be a chemist and at the age of 31 , he returned to the university and continued his career as a researcher. His efforts were rewarded when he was given the opportunity to study in England at the government expense at the age of 39. During his stay in Ramsay's lab at UCL, he discovered a new element. Ramsay suggested to him that it be named nipponium, Np.

After returning to Japan from the UK in 1906, Ogawa was appointed as a professor at the Tokyo Higher Normal School and continued his research using the thorianite mineral he brought back from the UK, as well as Japanese reinite and molybdenite. The additional work led to the publication of three papers in 1908-1909 (Ogawa 1908a, 1908b, 1909). In 1911 he moved to a newly-opened Tohoku Imperial University in Sendai, the largest city in northern Japan, as a professor of the College of Science. In the same year he was appointed as the dean of the College of Science (Fig. 1). He apparently had to devote much of his activities to negotiating with the ministry in Tokyo for the development and expansion of the new Imperial College. Unfortunately, his plan of visiting Europe in 1919 was cancelled since he unwillingly became the first-elected president of Tohoku Imperial University. The sample minerals for the extraction of nipponium were switched from thorianite and molybdenite to platinum sand. Since 1919 he had examined iridosmine containing iridium (77) and osmium (76), but time passed without significant results. It was in 1929 that a long-waited Siegbahn-type X-ray spectrometer arrived in Sendai (Kenjiro Kimura at the Imperial University of Tokyo obtained the same type of spectrometer in 1928). Ogawa's young colleague Shin'ichi Aoyama managed to overcome the initial problem of reaching a high vacuum and started to yield some data. Shortly before Aoyama's spectrometer became operational in 1930, Sakae Shinoda and Kimura at Tokyo reported at the Chemical Society Meeting in Tokyo the X-ray spectrum of rhenium in the sample extracted from molybdenite. Within a week, Ogawa fell in his laboratory and died of gallbladder disease three weeks later. Shinoda's work on rhenium was never published.

Fig. 1 Masataka Ogawa (1865-1930). Taken in ca. 1911. Courtesy of Tohoku University Archives

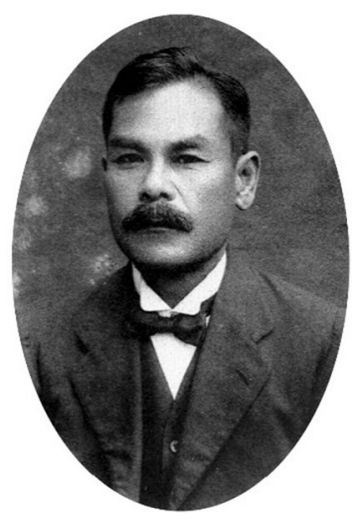


Ogawa was blessed with ten children; among them three of the sons were involved in scientific research. His second son Eijiro Ogawa (1904-1945) became a professor in the Faculty of Engineering at Kyushu Imperial University and continued his father's research on nipponium. Unfortunately, he died young before he could publish any of his results. His fourth and the youngest son Shiro and his fourth daughter Shige kept their father's crucibles, photographic plate, and other items of his later years. In 2004, these items were donated to Tohoku University as physical evidence to re-evaluate Ogawa's achievements, and are now carefully preserved as university archives and in museums. These items were designated as the 18th Chemical Heritage authorized by the Chemical Society of Japan in 2013.

Ogawa found a strong hint of a new element in the thorianite mineral during his research at Ramsay's laboratory. After returning to Japan, he improved extraction processes and isolated the new element and named it nipponium with the symbol Np. To report this discovery, Ogawa published two papers written in English in a Japanese journal, both of which were also published in the Chemical News (Ogawa 1908a, 1908b). He published another paper including the details of the experiments he performed at UCL in Japanese (Ogawa 1909). In the following, we refer to these papers as the first, second, and third paper. Unfortunately, many of the international reports evaluating Ogawa's achievements up to now seem to rely on insufficient knowledge of the contents of each of these papers, possibly because the third paper was written only in Japanese. Here we attempt to clarify his work using the diagrams detailing the chemical processes he reported. The first paper, "Preliminary Note on a New Element in Thorianite" (Ogawa 1908a), focuses on the properties of the new element nipponium (Fig. 2) obtained by an improved extraction processes from thorianite adopted in Japan as summarized in Fig. 7 in Appendix A. Ogawa added that nipponium was also obtained from reinite and molybdenite (Append. Fig. 8). The second paper, "Preliminary Note on a New Element Allied to Molybdenum" (Ogawa 1908b), mainly describes the element similar to molybdenum extracted from molybdenite (Append. Fig. 9). In addition, this paper reports that zirconium silicate crystals found in thorianite as an impurity may contain a substantial amount of nipponium (Append. Fig. 10). This description, although he denied in the third paper, apparently created misunderstanding by George Hevesy and others concerning the existence of nipponium. The third paper, "On New Elements in Thorianite" (Ogawa 1909), reports four candidates of new elements in thorianite. In Table 1, we summarize the main characteristics of these elements A to D, along with the element $\mathrm{E}$ described in the second paper and the element $\mathrm{F}$ contained in the zirconium silicate described in the third paper. The first one-third of the paper reviews previous composition analyses of thorianite by several investigators. It also describes the content of the zirconium silicate impurity crystals, correcting the statement in the second paper and stating that this silicate did not contain any noticeable amounts of nipponium (Fig. 10). The second one-third describes the details of the extraction processes Ogawa used at UCL as summarized in Append. Figs. 11 and 12. Nipponium was found with new optical spectral lines in alum. The contents of the last one-third are essentially the translation of the first paper into Japanese.

Among the conclusions in Ogawa's three papers, those intimately related to the new element nipponium are summarized as (1) to (5) below. He relied on a traditional precipitation method with ammonia to separate each element contained in the minerals to obtain hydroxides. Below, we add comments on the interpretation of the corresponding rhenium compounds in italic. A quantitative evaluation will be given in Section "Chemical characterization". 


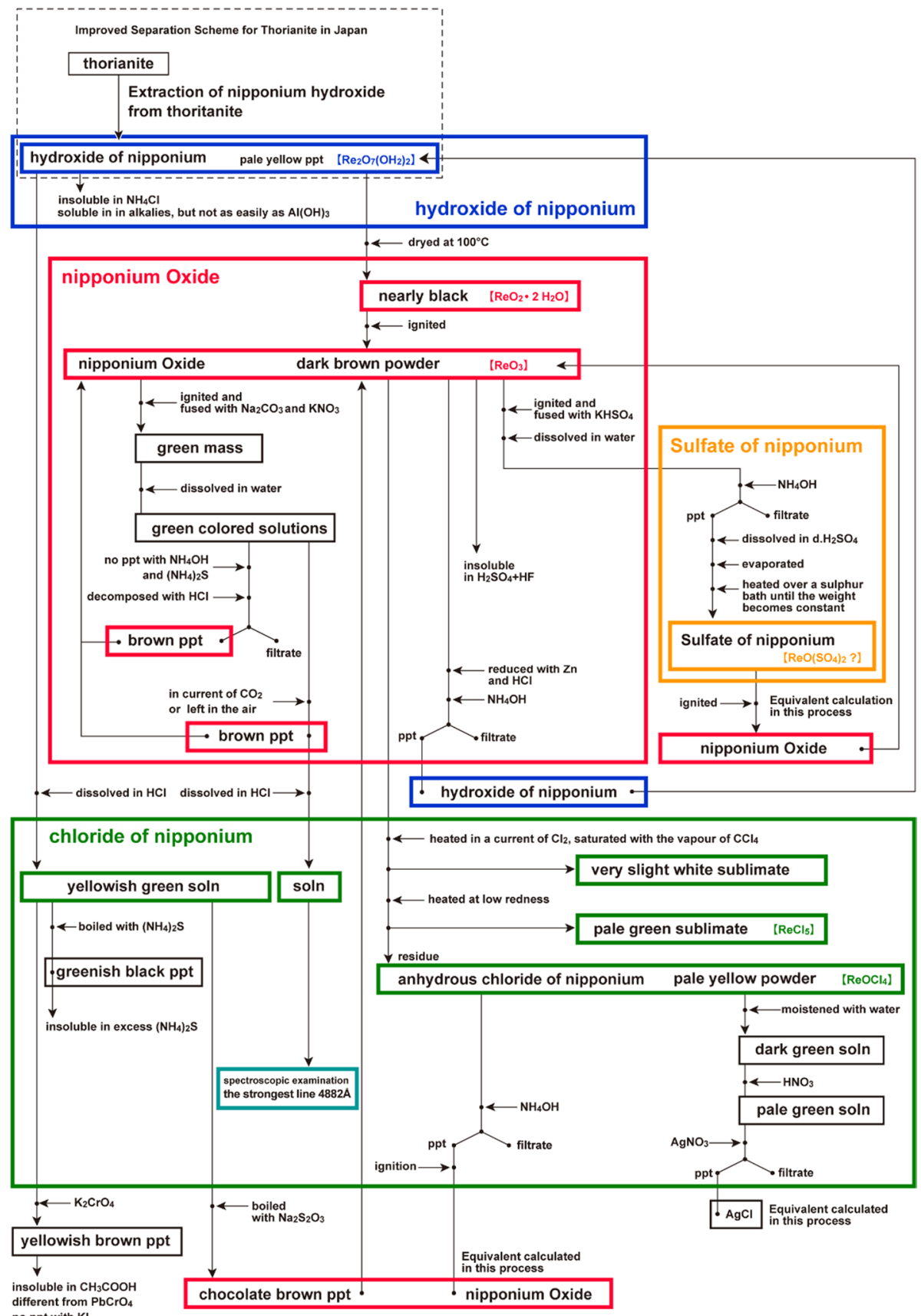

no ppt with KI

Fig. 2 Properties of Nipponium Compounds Revealed by Ogawa. Summary of chemical processes Ogawa adopted to convert nipponium hydroxide to the oxide, chloride, and sulfate. He also calculated the equivalents of sulfate from oxide, oxide from chloride, and silver chloride from chloride. The hydroxide was extracted from thorianite by improved chemical processes summarized in Append. Fig. 7. The rhenium compounds we interpreted are also indicated 
Table 1 Candidates of new elements reported by Ogawa. Appendix Figs. 7, 8, 9, 10, 11, 12 show their extraction processes. The last column represents our interpretations for the actual substance

\begin{tabular}{llll}
\hline & New element candidates by Ogawa & Source mineral & Possible substance \\
\hline A & Nipponium & Thorianite & Rhenium \\
B & New element allied to molybdenum & Thorianite & Mixture of molybdenum and rhenium? \\
C & New tin-group element by Evans & Thorianite & Low purity substance of B \\
D & Unknown substance appearing at the & Thorianite & Unknown \\
& $\quad$ position of bismuth & Thorianite & Thorium isotope \\
E & New radioactive element & $\begin{array}{c}\text { Segregated impurity } \\
\text { phase in thorianite }\end{array}$ & Trace of Hafnium \\
\hline
\end{tabular}

(1) [Hydroxide] The new element nipponium was obtained from thorianite as a hydroxide by an improved precipitation route adopted in Japan shown in Append. Fig. 7.

Yoshihara assigned rhenium oxyhydroxide $\mathrm{ReO}(\mathrm{OH})_{2}=\mathrm{H}_{2} \mathrm{ReO}_{3}[\mathrm{Re}(\mathrm{IV})]$ to this hydroxide (Yoshihara 1997). We argue that perrhenic acid $\mathrm{Re}_{2} \mathrm{O}_{7}\left(\mathrm{OH}_{2}\right)_{2}$ matches better to Ogawa's description.

(2) [Oxide] On drying at $100{ }^{\circ} \mathrm{C}$, the hydroxide became nearly black oxide, which turned into a dark brown color after ignited.

Yoshihara assigned to these compounds $\mathrm{ReO}_{2} \cdot 2 \mathrm{H}_{2} \mathrm{O}$ and the disproportionated $\mathrm{ReO}_{2}+\mathrm{Re}_{2} \mathrm{O}_{7}$. The color of the former is indeed nearly black, but the latter gray-black and pale green-yellow. We assign the latter oxide as $\mathrm{ReO}_{3}$, which is in dark red color and consistent with the reactions in (3) below.

(3) [Sulfate] This oxide was insoluble in acids but became soluble in water after fusion with potassium hydrogen sulfate $\mathrm{KHSO}_{4}$. The oxide thus dissolved in dilute sulfuric acid was evaporated to dryness and heated sufficiently in "sulfur bath" to form a sulfate.

Yoshihara assumed this sulfate as the oxysulfate $\mathrm{ReO}\left(\mathrm{SO}_{4}\right)_{2}$, which is little known in literature.

(4) [Chloride] The nipponium oxide yielded a non-volatile anhydrous chloride by heating in a chlorine gas stream saturated with carbon tetrachloride vapor. The chloride dissolved in water and formed a pale green solution, which gave a characteristic line spectrum at a wavelength of $4882 \AA$ and with two weaker lines in the green-blue optical region.

Yoshihara interpreted this chloride as rhenium oxytetrachloride $\mathrm{ReOCl}_{4}$.

(5) [Equivalent and atomic weight] Nipponium is divalent with an equivalent of 50 and an approximate atomic weight of 100 . This element probably fills the gap between molybdenum and ruthenium.

Yoshihara assumed the hexavalent state in the reactions among the oxide, chloride, and sulfate, and derived the atomic weight of 185.2, consistent with that of rhenium (186.2).

Now we describe Ogawa's three papers in more detail. Thorianite was available as small black pieces with a maximum dimension of about $1 \mathrm{~cm}$ and with a specific gravity of about 9 (Dunstan and Blake 1905). Figure 3 represents a photo of a typical thorianite mineral. As described in the box at the top of Fig. 12, Ramsay purchased $250 \mathrm{~kg}$ of thorianite from Mr. Holland in Ceylon (now Sri Lanka), all of which had been chemically treated with 
Fig. 3 Thorianite mineral. The orange-colored impurity compound on the surface mainly contains zirconium silicate

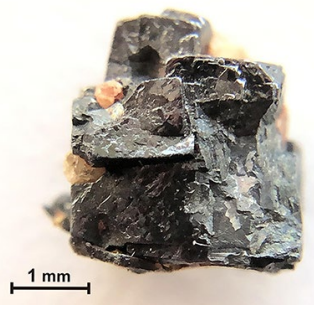

potassium hydrogen sulfate at Thomas Tyrer and Co. Ltd. of Stirling Chemical Works for the purpose of collecting helium (Ramsay 1904). Ramsay gave different samples after different chemical treatments to the researchers working on thorianite in his lab, including Ogawa, Otto Hahn, and Clare de Brereton Evans (Ramsay 1904; Hahn 1905; Evans 1908). Ogawa was given $1.5 \mathrm{~kg}$ of the hydrogen sulfide $\left(\mathrm{H}_{2} \mathrm{~S}\right)$ precipitate, and his analysis of the samples revealed several candidates of new elements (Ogawa 1909). We note that the precipitate he used was only a small portion of the processed thorianite available in Ramsay's lab. Ogawa reported this work in the third paper only in Japanese; we simplify the chemical processes adopted at UCL in Fig. 11 and show the full details in Fig. 12. As summarized in Table 1, Ogawa reported a total of six candidate materials of new elements, which we designate as $\mathrm{A}$ to $\mathrm{F}$, in his three papers. We added our interpretations on these elements in a modern perspective in Table 1. Among them, the element A concerns the main discovery, i.e., nipponium, and is the main topic of the first paper (Ogawa 1908a). The second paper dealt mainly with B, the claimed new element allied to molybdenum (Fig. 12), as well as with other new element candidates C, E, and F (Ogawa 1908b). The element D is described only in the third paper.

Shown as A in Figs. 11 and 12 is "nipponium", of which he reported the characteristic new optical spectral peaks in alum while he was at UCL. Ogawa discovered traces of this new element A relatively soon after his arrival in London and planned to publish this finding in November of that year (Ogawa 1904). However, he could not gather conclusive evidence and postponed the announcement. He continued his intensive efforts and by the time he returned to Japan in the spring of 1906 he obtained a lot of information concerning the efficient extraction process from thorianite. Before leaving the UK, Ogawa purchased $10 \mathrm{~kg}$ of the thorianite mineral from Ceylon, $6 \mathrm{~kg}$ of which consisted of smaller pieces, at most 2 to $6 \mathrm{~mm}$ large, and the other $4 \mathrm{~kg}$ was sandy with smaller crystals (Ogawa 1909). With Ramsay's permission, he also brought back to Japan the hydroxide precipitate obtained by the A route shown by the blue box in Fig. 12, as well as $100 \mathrm{~g}$ of the sulfur-containing precipitate shown by the red box at the bottom right of Fig. 12. He continued experiments in Japan using these three kinds of materials.

The improved extraction scheme of nipponium adopted in Japan is shown in Fig. 7. The initial step with boiling concentrated nitric acid yielded $30 \mathrm{~g}$ of precipitate from $1 \mathrm{~kg}$ of the finely powdered thorianite mineral. Even in this scheme, the amount of the nipponium oxide he obtained was only a few tens of a milligram from $1 \mathrm{~kg}$ of thorianite. Thus, he applied the same extraction scheme to the ammonia precipitate brought back from UCL (most probably the precipitate indicated by the blue box in Fig. 12) and obtained a total of about $100 \mathrm{mg}$ of oxide to be used to evaluate the atomic weight as described in the first and third papers. Although he assumed divalent state for the nipponium compounds, he also commented in the second paper: 
It is possible that nipponium, instead of being divalent, as was supposed, may prove

to be a trivalent element, with an atomic weight of $150, \ldots$ (Ogawa 1908b)

In addition to the ammonia precipitation route in which he obtained the element A (nipponium), he investigated in detail the hydrogen sulfide precipitation route started by his colleagues (Büchner 1906; Evans 1908; Ogawa 1909). This route is shown in the left half of Figs. 11 and 12, which yielded the new element candidates B to D. The elements B and $\mathrm{C}$ were also obtained from the molybdenite mineral as described in the second paper (Fig. 8).

The second paper further documents a radioactive new-element candidate E (Fig. 11). This element may correspond to another unknown radioactive material suggested by Hahn in his report of the discovery of radio-thorium from thorianite (Hahn 1905). Thus, Ogawa and Hahn found similar radioactive elements from thorianite, but via slightly different chemical processes.

The new element candidate $\mathrm{F}$ was extracted from the orange-colored zirconium-silicide impurity crystals in thorianite (Fig. 3), by the procedure shown in Fig. 10. Prior to this analysis, Ogawa described in the second paper that this silicate with the specific gravity of only 4.5 might contain an equivalent amount of zirconium and nipponium. However, additional experiments soon revealed that the salt actually contained only a very small amount of nipponium, and furthermore it was extremely difficult to isolate it. Unfortunately, these results to correct the statements in the second paper were reported in the third paper written only in Japanese. Ogawa's initial confusion with the zirconium silicate may have caused serious misinterpretation in Hevesy's report (Hevesy 1925); we will discuss it further in Section "International evaluations".

\section{Yoshihara's re-evaluation of nipponium}

Since 1996 Yoshihara has shed light on Ogawa's original achievement based on numerous documents and on donated materials from Ogawa's family. Yoshihara made an extensive review of the articles and other documents written by Ogawa and other researchers at the time. Importantly, by reassigning the compositions of the nipponium compounds Ogawa reported, Yoshihara demonstrated that the atomic weight of nipponium matches with that of rhenium. He also analyzed the X-ray photographic plate and other items Ogawa left. Furthermore, he made composition analysis of the kinds of minerals used by Ogawa by modern high-sensitivity methods. Each time Yoshihara published the results of his investigations, new testimonies and information were delivered to him. After a number of updating reports, he emphasized his conclusion that nipponium Ogawa discovered was actually rhenium (Yoshihara 2008).

H. Kenji Yoshihara, born in 1929, became a full professor of the radiochemistry lab at Tohoku University in Sendai in 1982. This university was formerly Tohoku Imperial University, where Masataka Ogawa contributed significantly to its establishment as the president (1919-1928). Although Ogawa's name was known among his colleagues at the university during Yoshihara's tenure there ( -1993$)$, the achievements on nipponium were no longer discussed in detail. Yoshihara has strong expertise on the two elements technetium and rhenium, and naturally got interested in Ogawa's work. Nevertheless, he was busy with his own research and he only managed to publish a brief discussion of Ogawa's work in the on-campus newsletter (Yoshihara 1992). After becoming an emeritus professor, he devoted 
more time to research into Ogawa's achievements. Yoshihara has extensive knowledge on the properties of the group-seven elements, and through detailed examination of Ogawa's papers he realized that the properties of nipponium described by Ogawa were accurate enough to correspond to those of rhenium. These results were first presented at the symposium "Discovery of the Elements" held at KU Leuven, Belgium, in September 1996, and the presentation was published as a paper in 1997 (Yoshihara 1997). Since Yoshihara was not able to go to Belgium, Hiromichi Nakahara read the paper on his behalf. Following this work, a number of testimonies reached Yoshihara from researchers who knew Ogawa at the time of his activities. In addition, Yoshihara conducted some verification experiments. Encouraged by these results, the Ogawa family presented him Ogawa's belongings, which provided compelling evidence. We note that Hiroshi Onishi suggested that Ogawa's nipponium may correspond to rhenium (Onishi 1990, 2009), but it was Yoshihara who first presented solid evidence and interpretations to identify Np as Re (Yoshihara 1997, 2004). Yoshihara's achievements were critically cited in a book by Eric Scerri (2013), and Yoshihara responded by pointing out various misunderstandings and typos in the book (Yoshihara 2015). We reexamine their arguments and attempt to resolve some of the issues stemming from their miscommunications in this paper (Appendix B).

Yoshihara extensively investigated Ogawa's achievements on the new elements based on the following resources (Yoshihara 1997, 2000, 2008). Firstly, he carefully examined the descriptions of the papers by Ogawa and his colleagues. Yoshihara conjectured that if nipponium were rhenium, the chemical processes Ogawa described actually produce (ReO) $\mathrm{Cl}_{4}$, instead of $\mathrm{ReCl}_{2}$. This conjecture leads to the atomic weight of 185.2, close to that of rhenium, 186.2 (Yoshihara 1997). Yoshihara also reinterpreted Ogawa's assignments of the composition of the oxide $\mathrm{NpO}$ to $\mathrm{ReO}_{2}+\mathrm{Re}_{2} \mathrm{O}_{7}$ and sulfate $\mathrm{NpSO}_{4}$ to $\mathrm{ReO}\left(\mathrm{SO}_{4}\right)_{2}$, which lead to the atomic weight consistent with that of rhenium (Yoshihara 1997).

Moreover, the optical emission spectra of nipponium dissolved in dilute hydrochloric acid reported in the first paper reinforced this conjecture. Yoshihara also presented an argument that the slightly red-colored crystallites provided to Hevesy, from which he did not find any new elements except hafnium, were actually zirconium silicates commonly appearing as impurities in thorianite (Fig. 3). Thus, these crystallites are entirely different from the thorianite in which Ogawa discovered nipponium.

The second group of resources was oral evidence and articles by Ogawa's colleagues evidencing that nipponium was rhenium. This includes the testimonies by colleagues of Kimura who analyzed Ogawa's sample by X-ray spectroscopy at the Imperial University of Tokyo in 1930. They wrote to Yoshihara that Kimura confessed "Ogawa's sample was beautiful rhenium indeed" (Yoshihara 2000). In addition, Shinoda, a colleague of Kimura at Tokyo, reported that molybdenite from Japan contained rhenium at the general meeting of the Chemical Society of Japan in 1930 about a month before Ogawa died. Furthermore, according to the letter Yoshihara received from a former assistant of Ogawa's second son Eijiro at Kyushu Imperial University, Eijiro continued experiments to look for the element 43 after his father died, but in 1944 Eijiro recognized that nipponium was actually rhenium (Yoshihara et al. 2002, 2005; Yoshihara 2004).

The third comes from the analyses on Ogawa's instruments, samples and an X-ray photographic plate from his last years of research activities. Yoshihara analyzed the elements contained in the instruments and the reagents provided by the Ogawa family (Yoshihara et al. 2002; Yoshihara 2003, 2004, 2008). It was known that Ogawa switched the main source for the extraction of nipponium from thorianite, reinite, and molybdenite to 
platiniferous minerals sometime after 1917 and iridosmine after 1919. Although Ogawa never published these results, he briefly wrote about it in a local newspaper (Kahoku Shimpō Newspaper 1925a, 1925b, 1927). Furthermore, Yoshihara reanalyzed and confirmed that the X-ray photographic plate for a nipponium sample from the last year of Ogawa's life showed clear signals of rhenium (Yoshihara 2003, 2004, 2008; Yoshihara et al. 2005).

As the fourth resources of his conclusions, Yoshihara conducted a few verification experiments. He confirmed that a thorianite mineral indeed contains rhenium by electronprobe microanalysis (EPMA) as well as by X-ray fluorescence measurement with synchrotron radiation (Yoshihara 2004, 2008; Yoshihara et al. 2005). The former yielded perhaps the first clear confirmation that thorianite contains rhenium. (According to Ogawa's first paper, there must have been at least a few tens of a milligram of rhenium in a kilogram of thorianite, corresponding to a few tens of a ppm.) The latter revealed that a molybdenite mineral from Japan contained as much as $500 \mathrm{ppm}$ of rhenium. The presence of rhenium in various kinds of minerals studied by Ogawa indirectly supports the assignment of Ogawa's nipponium to rhenium. Yoshihara also confirmed by an additional experiment that an aqueous solution of rhenium chloride indeed shows the $4889 \AA$ emission spectral peak (Yoshihara 1999), consistent with what Ogawa reported.

Although the existence of nipponium had been questioned as a phantom element for nearly 70 years after Ogawa's death, Yoshihara re-evaluated Ogawa's work in a modern perspective with additional pieces of evidence, and made Ogawa's work widely recognized. For this achievement, Yoshihara was awarded the Prize of the Japanese Society for the History of Chemistry in 2008.

Yoshihara concluded that there are three main reasons to deduce that Ogawa actually extracted rhenium 17 years before it was reported by the Noddacks:

(1) The chemical reactions described in Ogawa's papers would lead to the compounds with the $(\mathrm{ReO})^{4+}$ unit, leading to the atomic weight agreeing with that of rhenium (186.2). We will discuss these reactions in Section "Chemical characterization".

(2) Ogawa's descriptions of the optical emission spectrum with three peaks in the greenblue color region, among which the strongest peak is at $4882 \pm 10 \AA$ (Ogawa 1908a) agree with the spectrum of rhenium with the strongest peak at $4889 \AA$. We will discuss this further in Section "Optical spectrum".

(3) The X-ray spectrum of Ogawa's sample clearly shows peaks corresponding to those of rhenium. We will provide a revision of Yoshihara's peak assignments in Section "X-ray spectrum”.

In the next section, we will introduce and point out some issues on Yoshihara's achievements of reexamining the chemical processes, as well as the X-ray spectrum of Ogawa's sample obtained around 1930 but had never been published by Ogawa's colleagues.

\section{Ogawa's nipponium and rhenium}

In this Section "Ogawa's nipponium and rhenium", we reexamine the chemical and physical properties of Ogawa's nipponium and Yoshihara's interpretations. We focus on what were not clear in Yoshihara's studies and revise some of his conclusions. 
Table 2 Re-assignments of the compounds to obtain nipponium oxide from the hydroxide

\begin{tabular}{|c|c|c|c|c|c|c|}
\hline \multirow{2}{*}{$\frac{\text { Compounds }}{\text { Hydroxide }}$} & \multicolumn{2}{|c|}{ Ogawa $(1908 a, b)$} & \multicolumn{2}{|l|}{ Yoshihara (1997) } & \multicolumn{2}{|l|}{ This paper } \\
\hline & $\mathrm{Np}(\mathrm{OH})_{2}$ & $\begin{array}{l}\text { Almost- } \\
\text { white pale } \\
\text { yellow }\end{array}$ & $\mathrm{ReO}(\mathrm{OH})_{2}=\mathrm{H}_{2} \mathrm{ReO}_{3}$ & - & $\mathrm{Re}_{2} \mathrm{O}_{7}\left(\mathrm{OH}_{2}\right)_{2}$ & Pale yellow \\
\hline $\begin{array}{l}\text { After dried } \\
\text { at } 100{ }^{\circ} \mathrm{C}\end{array}$ & & $\begin{array}{l}\text { Nearly } \\
\text { black }\end{array}$ & $\mathrm{ReO}_{2} \cdot 2\left(\mathrm{H}_{2} \mathrm{O}\right)$ & Black & $\mathrm{ReO}_{2} \cdot 2\left(\mathrm{H}_{2} \mathrm{O}\right)$ & Black \\
\hline $\begin{array}{l}\text { After } \\
\text { ignited }\end{array}$ & $\mathrm{NpO}$ & Dark brown & $\mathrm{ReO}_{2}+\mathrm{Re}_{2} \mathrm{O}_{7}$ & $\begin{array}{l}\text { Gray-black+ } \\
\text { pale green- } \\
\text { yellow }\end{array}$ & $\mathrm{ReO}_{3}$ & Dark red \\
\hline
\end{tabular}

\section{Chemical characterization}

Assuming divalent state for the chloride, sulfate, and hydroxide, Ogawa reported the equivalent weight of about 50, which led him to conclude the atomic weight of 100. Yoshihara pointed out that the chemical reactions performed by Ogawa would lead to the tetravalent $\mathrm{ReO}$ unit; the oxychloride $\mathrm{ReOCl}_{4}$ instead of the chloride $\mathrm{NpCl}_{2}$ and the oxysulfate $\mathrm{ReO}\left(\mathrm{SO}_{4}\right)_{2}$ instead of the sulfate $\mathrm{NpSO}_{4}$ would lead to the atomic weight in agreement with 186.2 of rhenium. Nevertheless, the oxysulfate proposed in Yoshihara's re-interpretation is a material not widely known. In fact, Yoshihara mentioned this reaction in his 1997 paper and wrote "the conversion reaction is practically possible but not proved and left for experimental examination in the future".

In Table 2, we summarize our re-assignments of the compounds to obtain nipponium oxide from the hydroxide. Figure 4 represents the colors of the relevant rhenium oxides. Ogawa described that the pale-yellow hydroxide turned into nearly black after dried at $100{ }^{\circ} \mathrm{C}$, which turned into a dark brown oxide after ignited. The description of the paleyellow material matches with the solid form of the perrhenic acid $\operatorname{Re}_{2} \mathrm{O}_{7}\left(\mathrm{OH}_{2}\right)_{2}[\operatorname{Re}(\mathrm{VII})]$, known to form from a rhenium-oxide solution. In contrast, Yoshihara proposed the rhenium oxyhydroxide $\mathrm{ReO}(\mathrm{OH})_{2}=\mathrm{H}_{2} \mathrm{ReO}_{3}[\mathrm{Re}(\mathrm{IV})]$ (1997). Concerning the nearly-black material after dried at $100{ }^{\circ} \mathrm{C}$, we agree with Yoshihara to assign it to $\mathrm{ReO}_{2} \cdot 2\left(\mathrm{H}_{2} \mathrm{O}\right)$.

The dark-brown oxide obtained after igniting this nearly-black material would then correspond to $\mathrm{ReO}_{3}$, which is dark red in color. Yoshihara assigned this oxide after hydroxide was ignited as $\mathrm{ReO}_{2}$ and the oxide after the product from the chloride (or oxychloride) was ignited as the disproportionated mixture of $\mathrm{ReO}_{2}+\mathrm{Re}_{2} \mathrm{O}_{7}$, which is stoichiometrically equivalent to $\mathrm{ReO}_{3}$. However, the gray-black $\mathrm{ReO}_{2}$ and pale green-yellow $\operatorname{Re}_{2} \mathrm{O}_{7}$ do not match in color (Fig. 4). Furthermore, since $\mathrm{ReO}_{2}$ is soluble in acid, it is not consistent with

Fig. 4 Rhenium oxides with various oxidation states. From left to right: $\mathrm{ReO}_{2}$ [ $\left.\mathrm{Re}(\mathrm{IV})\right], \mathrm{ReO}_{3}$ $[\operatorname{Re}(\mathrm{VI})]$, and $\operatorname{Re}_{2} \mathrm{O}_{7}[\mathrm{Re}(\mathrm{VII})]$

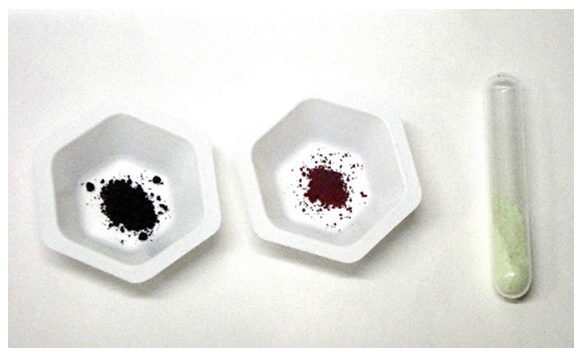


the description of Ogawa. It is also known that the disproportionated pair becomes $\mathrm{ReO}_{3}$ above $300{ }^{\circ} \mathrm{C}$.

Concerning the nipponium chloride obtained from the oxide, Yoshihara pointed out that the chemical reactions described in Ogawa's papers would result in the rhenium oxychloride $\mathrm{ReOCl}_{4}$, instead of rhenium chloride $\mathrm{ReCl}_{5}$. Then, the molar weight consistent with 186.2 for rhenium is derived. We agree with his re-assignment.

Finally for the nipponium sulfate, Yoshihara assumed it was actually the oxysulfate $\mathrm{ReO}\left(\mathrm{SO}_{4}\right)_{2}$, although it is little known as a compound. To synthesize this oxysulfate, Ogawa dissolved the oxide in water after fusion with potassium hydrogen sulfate. The oxide thus dissolved in dilute sulfuric acid was evaporated to dryness and heated sufficiently in "sulfur bath" to form the sulfate.

The reactions to convert among the oxide, "chloride", and sulfate are summarized in Table 3. Yoshihara's interpretations and our re-assignments give the same results concerning the evaluation of the equivalence and atomic weight of the new element. For the three reactions given in the table, the deduced atomic weight is 100.6, 100.6, and 98, respectively, for Ogawa's nipponium; it is 185.2, 186.4, and 176, respectively, for both Yoshihara's and our interpretations.

\section{Optical spectrum}

Yoshihara pointed out the agreement of optical spectra between nipponium and rhenium as the most important evidence that Ogawa's nipponium was actually rhenium. Ogawa documented three spectral lines in the green-blue region, of which the strongest line was at $4882 \pm 10 \AA$. In 1931, more than twenty years after Ogawa's measurement and six years after the Noddacks' discovery of rhenium (Noddack et al. 1925), William F. Meggers in the Bureau of Standards in the United States reported arc and spark emission spectra of rhenium in the visible region for the first time (Meggers 1931a). The spectrum in Fig. 5 is drawn based on the descriptions in Meggers' paper. The strongest line is at $4889.2 \AA$ followed by two lines at $4513.3 \AA$ (blue) and $5275.6 \AA$ (green). These results are consistent with Ogawa's description above. We note that instead of the peak at $4513.3 \AA$, Yoshihara assigned the peak at 5271.0 $\AA$ (1997); this peak, however, is too close to the 5275.6 $⿱$ peak to be resolved in Ogawa's work.

Let us emphasize that Ogawa described the previously-unknown optical spectra. This is essentially different from reports claiming new elements based on their X-ray spectra after the "correct answer" became known beforehand from Moseley's law. Some examples of the latter are: celtium as the element 72 (Dauvillier 1922) and illinium as the element 61 (Harris et al. 1926). These reports relied on the X-ray observations and eventually turned out to be false (Fontani et al. 2015).

Table 3 Key compounds and reactions to obtain the equivalence in Ogawa's paper, compared to Yoshihara's and our re-assignments

\begin{tabular}{|c|c|c|c|c|}
\hline Conversions & Mass ratio (g) & Ogawa $(1908 a, b)$ & Yoshihara (1997) & This paper \\
\hline Hydroxide to Oxide & - & $\mathrm{Np}(\mathrm{OH})_{2} / \mathrm{NpO}$ & $3 \mathrm{ReH}_{2} \mathrm{O}_{3} /\left(\mathrm{ReO}_{2}+\operatorname{Re}_{2} \mathrm{O}_{7}\right)$ & $\operatorname{Re}_{2} \mathrm{O}_{7}\left(\mathrm{OH}_{2}\right)_{2} / 2 \mathrm{ReO}_{3}$ \\
\hline "Chloride" to Oxide & $0.1092 / 0.0742$ & $\mathrm{NpCl}_{2} / \mathrm{NpO}$ & $3 \mathrm{ReOCl}_{4} /\left(\mathrm{ReO}_{2}+\operatorname{Re}_{2} \mathrm{O}_{7}\right)$ & $\mathrm{ReOCl}_{4} / \mathrm{ReO}_{3}$ \\
\hline Sulfate to Oxide & $0.1253 / 0.0747$ & $\mathrm{NpSO}_{4} / \mathrm{NpO}$ & $\begin{array}{l}3 \mathrm{ReO}\left(\mathrm{SO}_{4}\right)_{2} / \\
\quad\left(\mathrm{ReO}_{2}+\operatorname{Re}_{2} \mathrm{O}_{7}\right)\end{array}$ & $\mathrm{ReO}\left(\mathrm{SO}_{4}\right)_{2} / \mathrm{ReO}_{3}$ \\
\hline "Chloride" to $\mathrm{AgCl}$ & $0.0652 / 0.1120$ & $\mathrm{NpCl}_{2} / 2 \mathrm{AgCl}$ & $\mathrm{ReOCl}_{4} / 4 \mathrm{AgCl}$ & $\mathrm{ReOCl}_{4} / 4 \mathrm{AgCl}$ \\
\hline
\end{tabular}


Fig. 5 Optical spectrum of rhenium based on the report by Meggers (1931a). The reported values of the wavelengths and intensities are plotted, with the strongest peak at $4889.2 \AA$.

This spectrum is consistent with Ogawa's description in 1908 for his nipponium sample: "three spectral lines in the green-blue region with the strongest peak at $4882 \pm 10 \AA$

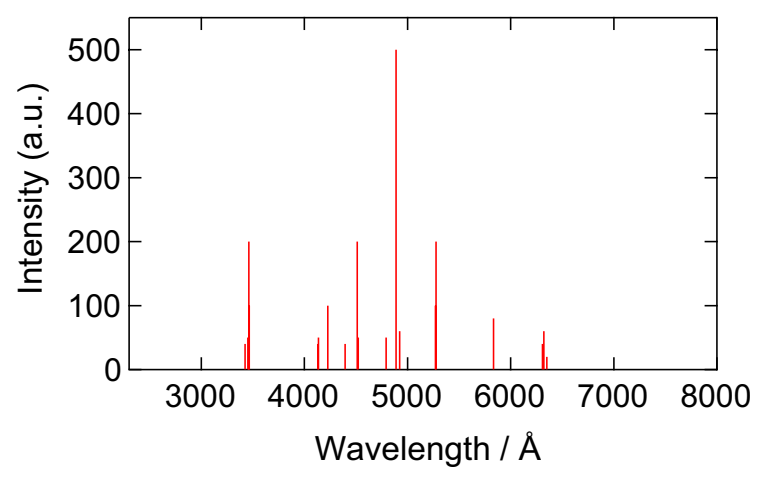

\section{X-ray spectrum}

We revisit the X-ray spectrum of nipponium. The spectrum was measured by Ogawa's assistant Aoyama in 1930 and shown to Ogawa just before Ogawa's death. A Siegbahntype X-ray spectrometer was used to obtain line spectra on a photographic plate (nonextant), whose image was read by a recording microphotometer to measure the intensity of the spectral lines. The copy of this photographic plate is shown in Fig. 6 a.

One immediately notices that the spectrum in Fig. 6a does not show ordinary spectral "peaks"; it rather indicates positive and negative peaks for each signal. We speculate that this is due to an inappropriate time-constant setting of the apparatus so that the peaks look like their derivatives, and we simulate the peaks accordingly. We also calibrated the wavelength scale based on the sinusoidal fringe pattern in Fig. 6a. The analysis below results in a slightly modified assignment of the elements to the peaks as shown below.

Since no detailed description remained on this spectrum itself, we speculate on the conditions of the measurement. In 1933 Aoyama and his co-worker wrote a series of reports (Aoyama and Fukuroi 1933a, 1933b), which were their first published reports on their X-ray spectrometer. The measurement of the X-ray spectrum of nipponium in 1930 must have been preliminary due to troubles such as a poor vacuum. There existed only two X-ray spectrometers in chemistry labs at that time in Japan, i.e., one was Aoyama's in Sendai and the other was in Tokyo. The one in Sendai was equipped with a recorder system to output the spectra (Yoshihara et al. 2005). This suggests that the apparatus and the experimental conditions for the measurement of nipponium were very similar to those described in the reports in 1933 (Aoyama and Fukuroi 1933a, 1933b).

Yoshihara considered that the sample used for the spectrum was nipponium with reference elements added to (or mixed with) it. He pointed out that the Roman numerals drawn on the photographic plate indicate the reference elements, where the numerals of I through VIII without VII correspond to rubidium (atomic number 37), strontium (38), yttrium (39), zirconium (40), niobium (41), molybdenum (42), and ruthenium (44) without technetium (43). We adopt his interpretation. These numerals also correspond to "Coil 1, 2, 3, 4, 5, 6, 8 series" at the bottom.

A sinusoidal curve on the photographic plate most probably indicates a 1-mm scale. Adding such a scale to an X-ray spectrum seems common at that time (Noddack et al. 1925). Aoyama described in his report in 1933 that the dispersion of their X-ray spectrometer was $11.4 \mathrm{xu} / \mathrm{mm}$ at the $\mathrm{K}$ line of chlorine $(1 \mathrm{xu}=100.21 \mathrm{fm})$ and $13.6 \mathrm{xu} / \mathrm{mm}$ at that 
(a)

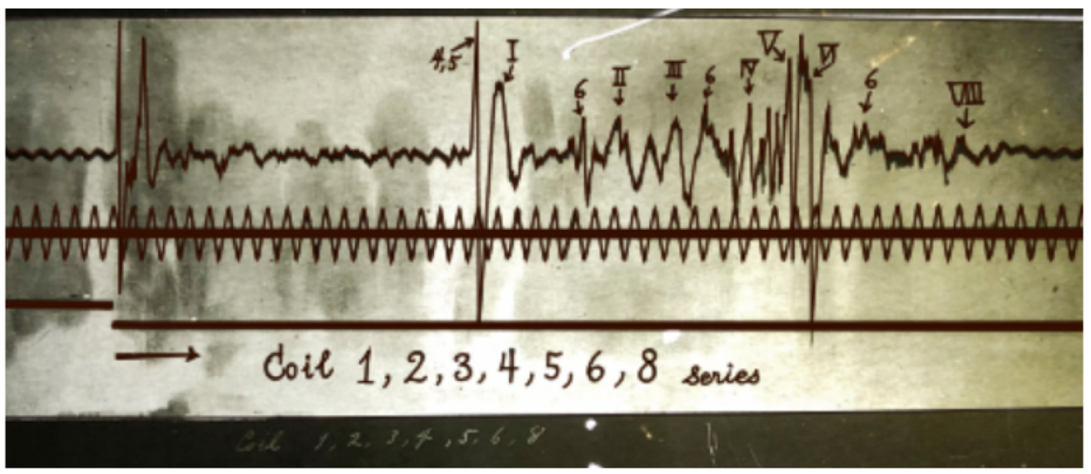

(b)

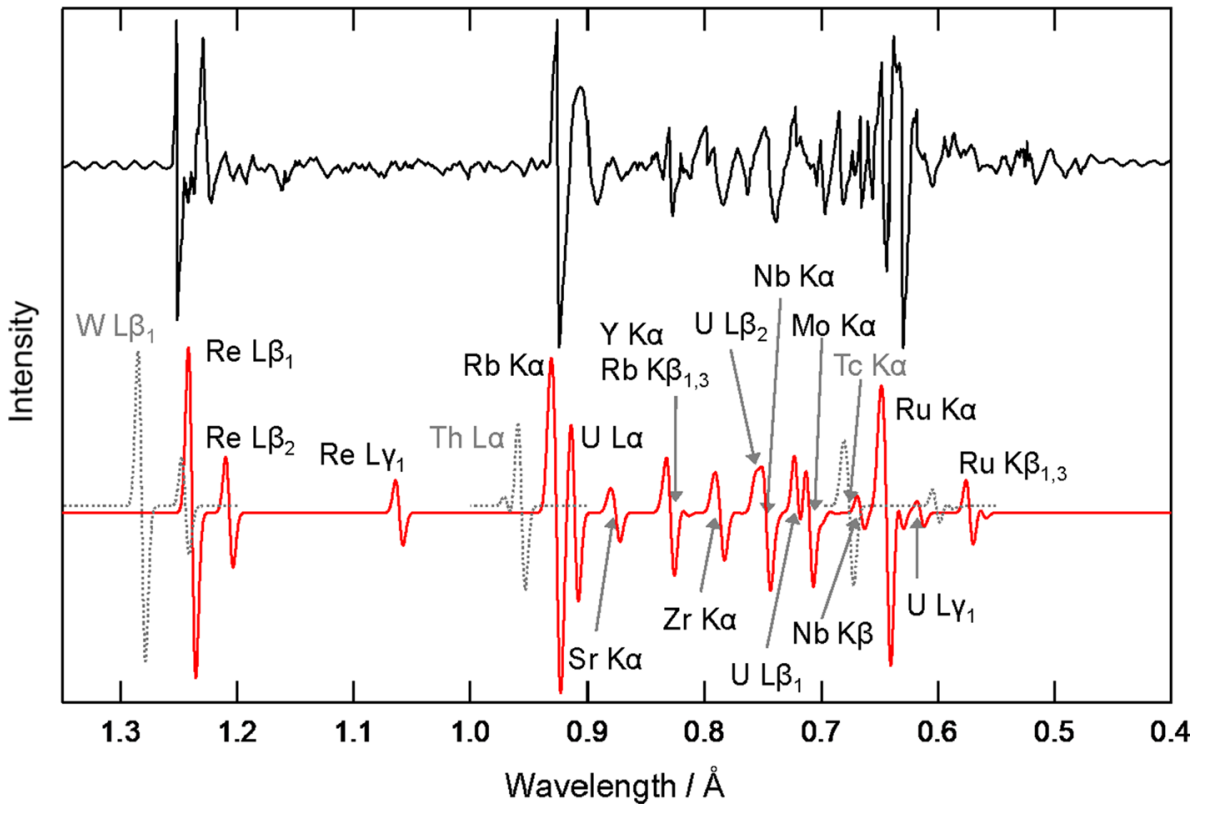

Fig. 6 Re-assignment of the X-ray peaks of Aoyama's photographic plate for Ogawa's sample. a Photographic plate of the X-ray spectrum by S. Aoyama at Tohoku Imperial University (1930). Reference elements were added to the "nipponium" sample extracted by Ogawa. The sinusoidal fringe patterns indicate 1-mm length on the plate. b (Upper) Aoyama's data after the horizontal scale is calibrated based on the fringe scale. (Lower) Simulated differential-peak spectrum with anticipated intensity ratios. The peak locations of technetium (Tc, 43), tungsten (W, 74), and thorium (Th, 90) are added for comparison

of potassium (Aoyama and Fukuroi 1933b). Based on this description, we estimated the wavelength at the region in question as follows: Bragg's law is given as

$$
\lambda=2 d \sin \theta
$$


where $\lambda$ and $\theta$ are the wavelength and the glancing angle of the X-ray, respectively, and $d$ is the interplanar distance of a lattice. Aoyama used calcite as the reflection crystal (Aoyama and Fukuroi 1933a) with $d=3.029 \AA$ at $18{ }^{\circ} \mathrm{C}$. The peak position $l$ on the plate is related to the scattering angle $\theta$ and the distance $r$ between the reflection crystal and the plate as:

$$
2 \theta=l / r
$$

From (1) and (2), we obtain

$$
\frac{d \lambda}{d l}=\frac{d}{r} \cos \frac{l}{2 r}
$$

This dispersion relation gives the conversion from the position on the plate to the wavelength. Both values in Aoyama's paper are well reproduced for $r=171.8 \mathrm{~mm}$. This value of $r$ is similar to that in his report in 1933, where he wrote that $r=181.74 \mathrm{~mm}$ (Aoyama and Fukuroi 1933b). Because the reference elements of rubidium through ruthenium show their $\mathrm{K}$ lines around 1 through $0.5 \AA$, we calculate the wavelength shift per $1 \mathrm{~mm}$ on the photographic plate at 1.0 and $0.5 \AA$ to be $0.0174 \AA / \mathrm{mm}$ and $0.0176 \AA / \mathrm{mm}$, respectively. Considering the precision of the positions on the photographic plate, such non-linearity is negligible and we assume the linearity in the whole wavelength region between 0.6 and $1.2 \AA$. In fact, when we take the $\mathrm{Rb}$ peak as the reference, the nonlinearity amounts to $\pm 0.001 \AA$ at the edge.

As stated above, one peculiar characteristic of the spectrum is that every feature seems like a first-derivative of a normal (Gaussian) spectral peak. It was not known why such an unusual profile was recorded. We speculate that the time constant in the output circuit might have been too short, and we assume that the profiles on the photographic plate were a first-derivative of an X-ray spectrum of the sample.

Based on the assumptions above, the spectrum in Fig. 6a was redrawn. Figure 6b shows a linearized drawing of the spectrum on the photographic plate (upper) and the first-derivative of the simulated spectrum (lower). The upper spectrum was calibrated along the horizontal axis so that each interval of the sinusoidal curve was set to be $0.0175 \AA$, and shifted horizontally so that the simulated zero-crossing of $\mathrm{Rb} K \alpha(0.926 \AA)$ coincides with that of the data. Spectral simulation was performed (Deslattes et al. 2005; Thompson et al. 2009; Goto et al. 1987) under the assumption that the abundance of each element was as follows: (Re: Rb: Sr: Y: Zr: Nb: Mo: Ru: U)=(8.5: 1.3: 0.2: 0.2: 0.3: 0.5: 0.5: 1.0: 1.8).

The two spectra in Fig. 6b agree well. The left-most features can only be assigned as the rhenium $L \beta$ peaks. In fact, the anticipated simulated spectrum for the adjacent element, tungsten, shown with a broken line, do not match. This reassures that Ogawa's nipponium sample consists of rhenium. At the same time, we identified the peaks from uranium; this supports that the sample was extracted from thorianite.

Table 4 compares the peak assignments by the original X-ray photographic plate by Aoyama in 1930, by Yoshihara (2004), and in the present paper. Yoshihara's assignment and ours are different mainly with respect to thorium. He considered that thorium remained in the nipponium sample with the abundance of six times as large as that of uranium while we assumed that it was absent. Figure $6 \mathrm{~b}$ also includes the simulated spectrum of thorium as a broken line, which does not match as well. Based on our calibration along the horizontal axis and assumption that profiles are the first-derivative of normal peaks, we find that much better overall fitting is obtained if the large peak in the middle of the spectrum at $0.93 \AA$ does not correspond to the $\mathrm{L} \alpha_{1}$ line of thorium as Yoshihara considered, but to the positive part of the first-derivative of the $\mathrm{K} \alpha$ line of rubidium. The absence of thorium is 
Table 4 Elemental assignments of the X-ray photograph features in Fig. 6 and the corresponding wavelengths

\begin{tabular}{|c|c|c|c|c|}
\hline \multirow[t]{2}{*}{ Aoyama (1930) } & \multirow[t]{2}{*}{ Yoshihara (2004) } & \multicolumn{3}{|l|}{ This paper } \\
\hline & & Assignment & $\begin{array}{l}\text { Wavelength }(\AA) \text { at the } \\
\text { zero-crossing in Fig. } 6 \mathrm{~b}\end{array}$ & Wavelength $^{* 1}(\AA)$ \\
\hline & $\operatorname{Re} L \beta_{1}$ & $\operatorname{Re} L \beta_{1}$ & 1.245 & 1.239 \\
\hline & $\operatorname{Re} \mathrm{L} \beta_{2}$ & $\operatorname{Re} \mathrm{L} \beta_{2}$ & 1.225 & 1.207 \\
\hline 4, 5 (Th, Pa?) & $\operatorname{Th} \mathrm{K} \alpha$ & $\mathrm{Rb} \mathrm{K} \alpha$ & $0.926^{* 2}$ & 0.926 \\
\hline \multirow[t]{2}{*}{$\mathrm{I}(\mathrm{Rb})$} & $\mathrm{Rb} \mathrm{K} \alpha$ & $\mathrm{U} \mathrm{L} \alpha$ & 0.898 & 0.911 \\
\hline & $\mathrm{UL} \alpha$ & $\mathrm{Sr} \mathrm{K} \alpha$ & 0.875 & 0.876 \\
\hline $6(\mathrm{U})$ & $\operatorname{Sr} \mathrm{K} \alpha$ & $\mathrm{Y} \mathrm{K} \alpha$ & 0.829 & 0.829 \\
\hline II (Sr) & $\mathrm{Y} \mathrm{K} \alpha$ & $\mathrm{Zr} \mathrm{K} \alpha$ & 0.790 & 0.787 \\
\hline III (Y) & $\mathrm{Zr} \mathrm{K} \alpha$ & $\mathrm{Nb} \mathrm{K} \alpha$ & 0.745 & 0.747 \\
\hline $6(\mathrm{U})$ & $\mathrm{Nb} \mathrm{K} \alpha, \mathrm{U} L \beta_{2}$ & $\mathrm{UL} \beta_{1}$ & 0.706 & 0.719 \\
\hline IV (Zr) & Mo K $\alpha, \mathrm{U} L \beta_{1}$ & Mo K $\alpha$ & 0.683 & 0.710 \\
\hline $\mathrm{V}(\mathrm{Nb})$ & $\mathrm{Nb} \mathrm{K} \beta$ & $\mathrm{Ru} \mathrm{K} \alpha$ & 0.647 & 0.644 \\
\hline VI (Mo) & $\mathrm{Ru} \mathrm{K} \alpha, \mathrm{Th} \mathrm{L} \gamma$ & $(\mathrm{Ru} \mathrm{K} \alpha)$ & 0.631 & - \\
\hline $6(\mathrm{U})$ & $\mathrm{UL} \gamma$ & $\mathrm{Ru} \mathrm{K} \beta_{1,3}$ & 0.580 & 0.573 \\
\hline VIII (Ru) & $\mathrm{Ru} \mathrm{K} \beta$ & - & 0.493 & - \\
\hline
\end{tabular}

${ }^{* 1}$ Wavelengths in the literature (Deslattes et al. 2005). ${ }^{* 2}$ Adjusted so that this value coincides with that of the literature

consistent with Ogawa's process on thorianite as shown in a double-framed box in Append. Fig. 7; it is known that thorium is readily removed as the precipitate $\operatorname{Th}\left(\mathrm{C}_{2} \mathrm{O}_{4}\right)_{2}$ with oxalic acid from thorianite, while the process of removing uranium is not as straightforward. Thus, the Th/U ratio does not have to be the same as that of $\alpha$-type thorianite.

\section{Assessments of Ogawa's nipponium}

In this Section “Assessments of Ogawa's nipponium”, we first review how Ogawa's nipponium has been recognized internationally (Section "International evaluations"). In particular, we explain why some misunderstanding was created and spread in various literature. In Section "Domestic recognitions and reactions", we review how Ogawa's discovery was welcomed in public in Japan and discuss why his colleague scientists in Japan were not able to reveal its correct identity openly. Finally in Section "By Ogawa himself", we attempt to analyze how Ogawa himself recognized the identity of nipponium over the years of his research.

\section{International evaluations}

The identification of Ogawa's nipponium as rhenium, revealed by Yoshihara, is now widely recognized internationally as follows. In The Element, a book with beautiful 
photographs of elements, Theodore Gray (2009) fully embraced Ogawa's discovery and described it as follows:

Rhenium was the last stable element to be discovered, in 1925 in Germany. It was probably discovered earlier, in 1908 in Japan by Masataka Ogawa, and it might be known as "nipponium" if only Ogawa had not thought, and claimed, that he had discovered the element directly above it in the periodic table - element 43 , which we know as technetium.

Fontani et al. (2015), in their book The Lost Elements, introduced Yoshihara's achievements as well as criticized Western science to accept Hevesy's misunderstanding on the nipponium sample.

The Rhenium page of the "Elementymology \& Elements Multidict" website, an encyclopedia of elements established by Peter van der Krogt, explains that Ogawa's nipponium can be regarded as the 75th element from the modern chemical viewpoint (Van der Krogt 2010). The Rhenium page of the Periodic-Table website of the Royal Society of Chemistry (RSC) (2021) describes that Ogawa reported the discovery of a new element based on an unknown emission spectrum, but that his claim was discounted because he wrongly thought that it was eka-manganese. It also describes that the photographic plates found later proved that he had discovered rhenium. A similar claim can be found in John Emsley's book (2011), which assigns nipponium to the element 75, evidenced by Ogawa's original photographic plate.

Despite these current international recognitions of nipponium as rhenium, there are remaining issues and criticisms against such an assignment even today, as we outlined in Section "Introduction" (Scerri 2013). Yoshihara gave a counterargument to Scerri's concerns (Yoshihara 2015). In Appendix B, we present the full translation of Yoshihara's paper written in Japanese with our notes added. Below, we trace the history of evaluations as well as misunderstandings on Ogawa's work.

The contents of the two papers reported by Masataka Ogawa in 1908 (1908a, 1908b) were cited properly in the period shortly after their publications, but later they were often mis-interpreted. In a chapter of the 1909 annual report of the Chemical Society (London), Hugh Marshall correctly described the contents of Ogawa's papers (Marshall 1909), including the discovery of nipponium and its chemical properties in the first paper, and the finding of a new element with similar properties to molybdenum in the second paper, as well as the discovery of another new element as a radioactive oxide from thorianite in the second paper. In the same year, Frederick Henry Loring placed nipponium as $\mathrm{Np}$ between Mo and $\mathrm{Ru}$ in his own periodic table (Loring 1909). This is the position Ogawa claimed for nipponium in the first paper. In 1916, Hugo Stintzing introduced Werner's periodic table that lists $\mathrm{Np}$ with a question mark placed in the same position as Loring's (Stintzing 1916). Nevertheless, neither Loring nor Stintzing quoted Ogawa's papers or commented on his findings.

In 1925, two papers were published that shook Ogawa's discovery. One reported the results of X-ray spectroscopic analysis of silicate from thorianite that was supposed to contain nipponium (Hevesy 1925), and the other reported on the discovery of elements 43 and 75 (Noddack et al. 1925). Hevesy concluded that the sample was zirconium silicate containing $2 \%$ of hafnium. The Noddacks did not cite Ogawa's work and did not mention his findings. As we describe below, misconceptions concerning Ogawa's nipponium largely stem from the misinterpretations of Hevesy's paper. 
By quoting Ogawa's first paper only, Hevesy gave a very short description on nipponium:

..., Ogawa believed to have found, in the thorianite, the silicate containing a new element, the nipponium. Mr. R.-B. Moore, senior chemist of the Bureau of Mines in Washington, had the extreme kindness to send us some of the crystals of silicate containing nipponium obtained by Ogawa. These crystals were composed, essentially, of zirconium silicate having a content of $2 \%$ of hafnium (Hevesy 1925, p. 143).

Hevesy's statement that silicate crystals obtained by Ogawa contained no new elements except hafnium seems to have created misunderstanding by some authorities in later years. Ogawa's papers describe nipponium in thorianite from two entirely different sources. The reasons these two kinds of "nipponium" were mixed-up in some literatures are probably as follows: In the first paper, Ogawa reported the discovery of the new element nipponium through chemical-extraction processes of thorianite and described its optical and chemical properties. Unfortunately, in the second paper Ogawa mentioned that the silicate segregated as an impurity in the thorianite mineral may be an abundant source of nipponium. The latter statement was denied by himself in the third paper published in the following year, written only in Japanese. Furthermore, a few years later, Matsusuke Kobayashi analyzed the impurity phase of the thorianite mineral and confirmed that zirconium silicate was the main component, but published these results in Japanese and in a Tohoku Imperial University journal (Kobayashi 1912a, 1912b). Domestic publications both by Ogawa and Kobayashi made their results unfamiliar to Western researchers. Moreover, Hevesy only cited Ogawa's first paper which does not mention the silicate at all. Such treatment seems to have created prolonged and unfortunate misunderstanding.

Let us look into some more details of the silicate Ogawa reported. As seen in Fig. 3, thorianite ore typically contains small impurity segregates of translucent red to yellow crystals. In the second paper, which mainly reports the extraction processes of a new element allied to molybdenum from Japanese molybdenite, Ogawa briefly mentioned the impurity silicate from the thorianite mineral:

It may be here stated, by way of parenthesis, that a new rich source of nipponium has been discovered. ... The specific gravity of the mineral is 4.5 , being about onehalf of that of thorianite. This mineral was once thought to be zircon, but, on further examination, it has been found that it is a double silicate of zirconium and nipponium (Ogawa 1908b).

This statement was evidently incorrect and Ogawa himself denied it immediately in the third paper published in the following year. There he stated that most of the metals that could be separated from this silicate were zirconium, and that the silicate contained very small amounts of new elements (Fig. 10). We speculate below that this new element inseparable from zirconium might have been hafnium, but Ogawa was far from characterizing its chemical properties.

Did Hevesy really analyze the silicate crystals "obtained by Ogawa"? Ogawa's colleague Toshiyuki Majima reported that Hevesy exhibited a hafnium fluoride crystal and a red fine-grained solid next to it as nipponium at the 5th Annual Meeting of the International Society of Chemistry in Copenhagen in 1923 (Majima 1925). It is plausible that what Majima saw was a part of the sample analyzed by Hevesy, but Ogawa clearly told Majima that he never provided such materials to anyone in other countries. Ogawa's 
second paper (Ogawa 1908b) was based on his analysis in Japan of the silicate crystals taken from thorianite he brought back from the UK.

As described in Section "Ogawa's work" and shown at the top of Fig. 11, most of the composition analyses of thorianite in Ramsay's lab were performed using the materials after chemical treatment with potassium hydrogen sulfate (Ramsay 1904). It is unlikely that these contained the silicate crystals as described by Hevesy. The amount of the unprocessed thorianite mineral used in the analyses reported by the researchers in Ramsay's lab was only as much as $24 \mathrm{~g}$ (Büchner 1906). No studies were published from Ramsay's group on processes of the treatment of thorianite directly from its minerals. By the time Ogawa purchased $10 \mathrm{~kg}$ of thorianite minerals for his studies in Japan in 1906, Ramsay's lab might have also obtained more unprocessed thorianite minerals.

Richard B. Moore, who probably provided the silicate crystals originating from the thorianite minerals to Hevesy, wrote a biography of Ramsay two years after Ramsay passed away (Moore 1918). He met Ramsay at a meeting in London in 1908, the same year that Ogawa published that incorrect information of nipponium in the silicate based on his study in Japan. It is possible that Moore obtained some thorianite minerals along with the impurity silicate at Ramsay's lab, as Yoshihara speculated (Yoshihara 2008).

Hevesy found $2 \%$ of hafnium in the sample he described as "crystals of silicate containing nipponium obtained by Ogawa". If the new element nipponium reported 15 years prior to the discovery by Dirk Coster and Hevesy (1923a, 1923b) were hafnium, Ogawa would have been the discoverer of hafnium. However, it is natural that Hevesy did not mention this linkage since the properties of nipponium Ogawa described in the first paper were dissimilar to those of hafnium. Hevesy should have cited Ogawa's second paper which mentioned the silicate impurity; instead, he only cited the first paper that described the properties of nipponium contained in thorianite.

Concerning the new element contained in the zircon impurities in thorianite minerals, Ogawa wrote about it in the third paper, after correcting his previous mistake and stated that the zircon impurities actually contained little nipponium. As shown as $\mathrm{F}$ in Fig. 10, he tried to remove zirconium from the solution of zircon crystals by potassium sulfate precipitation, but it turned out that the solution with a new element still contained substantial zirconium. It was very difficult to isolate the new element from the zirconium, and by the time it was nearly isolated, the amount was too little to characterize its properties. From this description, we may speculate that Ogawa was close to finding hafnium as early as in 1909, but did not succeed in isolating enough amount for its characterization.

In 1969 a prestigious Dutch historian of chemistry Johannes Willem van Spronsen emphasized that nipponium was not hafnium in the chapter 'prediction of hafnium' (Van Spronsen 1969). Citing Ogawa's first paper, he wrote that Ogawa discovered nipponium as a silicate in thorianite and other minerals. He then quoted Hevesy's report that Ogawa's silicate was zirconium silicate containing $2 \%$ of hafnium. He continued that Ogawa's report did not satisfy the chemical properties to identify nipponium to hafnium. Just like Hevesy, he cited only the first paper, although his description relied on the incorrect content of the second paper. It is a pity that van Spronsen's renowned book does not mention Ogawa's achievements on nipponium properly.

In the book on the history of the discovery of chemical elements the Trifonov brothers in the Soviet Union (now Russia) presented a different view and stated that what Ogawa dealt with as a new element was probably hafnium (Trifonov and Trifonov 1982). In this 
book, the year of the discovery of nipponium was mentioned without citing Ogawa's papers. However, nipponium was considered to be a hafnium precursor, and acknowledged the achievements of the discovery of new elements to some extent.

In his 2013 book, American historian of chemistry Eric Scerri quoted Hevesy's denial of Ogawa's discovery, but made no mention of the relationship between nipponium and hafnium (Scerri 2013). Hevesy's description of mixing the two sources of nipponium has left long and widespread influence.

In contrast to Hevesy's treatment of nipponium, John Gerald Druce implied a possible relationship between nipponium and rhenium in his book Rhenium (Druce 1948). This is the first specialist monograph on rhenium extensively reviewing its chemical properties. He wrote that the properties of nipponium reported by Ogawa were similar to those of the claimed new elements by Evans (Evans 1908), as well as by others reporting the reactions corresponding in part with those of rhenium.

Let us mention two more examples that related Ogawa's nipponium to rhenium, which were also mentioned by Yoshihara (2008). Firstly, when Majima, who developed the chemistry department at Tohoku from its foundation, visited the University of Berlin in 1938, an inorganic chemist (probably Erich Tiede) asked Majima if nipponium was rhenium (Majima 1954). Secondly, Switzerland-born geochemist Victor Moritz Goldschmidt, well known for his classification of elements, pointed out that Ogawa's nipponium might have been a mixture of oxides of rhenium and molybdenum in his posthumous book edited by A. Muir (Goldschmidt 1954, p. 645).

\section{Domestic recognitions and reactions}

We now describe how Ogawa's announcement of the discovery of the new element nipponium was treated in the Japanese society and how scientists in Japan evaluated and reacted to it.

\section{Social recognition in Japan}

It was recognized that the academic level of research in chemistry in Japan was far behind the West at the end of the nineteenth century, when Ogawa became a researcher. Thus, the announcement of the discovery of a new element by Ogawa at the beginning of the twentieth century was welcomed enthusiastically as an epoch-making achievement. In fact, in Ogawa's doctoral diploma in 1910, it was stated that the discovery of nipponium was beyond the achievement of the individual, but that of the chemical society of Japan. In the same year, Ogawa received the Sakurai Prize from the Chemical Society of Tokyo as the first laureate of this award, which later became the Chemical Society of Japan Award. It is said that the reason why the Sakurai Prize was established even earlier than the Imperial Prizes in Japan was to reward Ogawa for his discovery. A number of resources from that period indicate that Ogawa's achievement was widely known not only to academia, but also to the imperial family, ministers, bureaucrats, and the general public. Until a few years before Ogawa died, national newspapers often covered stories on Ogawa's experiments on nipponium (Kato 1990).

Immediately after Ogawa's death, he received the prestigious imperial medal "Order of the Rising Sun, Gold and Silver Star". The official documents on his achievements, 
prepared by Tohoku Imperial University, the Ministry of Education, and the Bureau of Awards, described that Ogawa's discovery deeply impressed Japanese society to recognize that even the Japanese had sufficient ability to perform world-class research in chemistry; but it also mentioned that his study on nipponium was not completed (Imperial Cabinet of Japan 1930). It is plausible that when this document was prepared in July 1930 even the university authorities were not fully aware that the X-ray data started to reveal that nipponium was actually rhenium. Nevertheless, such controversial evidence for the true identity of nipponium soon became known even to some news media. In the following year, a news reporter for Tokyo Nichi-nichi Newspaper published a book on episodes in academia (Otsuka 1931, pp. 76-82); Torao Otsuka wrote in the chapter on Tohoku Imperial University that Ogawa pursued to discover a new element for his lifetime, and it was the 75th element.

However, as time passed without reproduction experiments or further development on nipponium, recognition of Ogawa's discovery gradually faded away. In the first issue of the Chronological Scientific Tables in Japan in 1925, published in the same year as the report by the Noddacks on the elements 43 (Ma) and 75 (Re), the Periodic Table of the Elements (p. 204) left the element names blank for both elements 43 and 75. In the second issue in 1927 (p. 226) both Ma and Re were listed, without mentioning Np.

\section{Reactions and evaluations by the chemists in Japan}

We will now examine why Ogawa's colleagues and the community of Japanese chemists did not promote the possibility that Ogawa actually isolated rhenium as early as in 1908 . This is perhaps not an issue of science alone, but one aspect of how science was performed in Japan in that period. We may divide it into three periods: before the new element rhenium (75) was discovered in 1925, before Ogawa's death in 1930, and after his death.

Concerning the first period until 1925, we examine how researchers and students in Ogawa's lab contributed to the study of nipponium. Ogawa's inorganic chemistry lab at the newly founded Tohoku Imperial University started in 1911, and in the same year Kobayashi and Aoyama were hired as an associate professor and a research associate, respectively. In 1918 Saichiro Nagami and Aoyama were appointed as lecturers in Ogawa's lab.

Kobayashi analyzed the content of thorianite using three to five grams of its minerals. He revealed that there are two variants in the thorianite minerals and he also revealed the contents of impurity phases including the silicate containing zirconium. He published these results both in Japanese (Kobayashi 1912a) and in English (Kobayashi 1912b). Partially because of the smallness of the amount of thorianite available, he could not detect new elements like nipponium nor hafnium. It was Aoyama who performed spectral analysis of these samples for Kobayashi's papers, including the identification of helium from the ore. After studying thorianite for a few years, Kobayashi had the opportunity to study in the USA from 1915. He returned to Sendai in 1918 to start the analytical chemistry lab as a professor.

Aoyama worked under Ogawa for about twenty years. He started as a student at the Tokyo Higher Normal School, where Ogawa worked as a professor after returning from UCL. Aoyama advanced to graduate school and in 1911 he moved to Sendai as a research associate in Ogawa's lab. Aoyama had assisted Ogawa's investigation on nipponium since he was a student (Ono 1930). By 1913, however, the main topics of Aoyama's study 
changed to the reaction between sulfurous acid anhydride and ammonia, as well as the properties of selenium. These topics were the extension of Ogawa's previous study under Divers in Tokyo. He left no research publication on nipponium. He once left the university for health reasons in 1915 but came back as a lecturer in 1918. Both Aoyama and Nagami studied platinum-group elements and received their doctoral degrees in 1923 and 1926, respectively, while helping Ogawa with his work on nipponium. Nagami later confessed that he had wished that Ogawa had not changed his attention to the minerals containing platinum-group elements (Kato 1990).

The first student in Ogawa's lab, Heihachiro Ono, described how young members of Ogawa's lab gave up studying nipponium because of the extreme difficulty to extract nipponium from thorianite (Ono 1930). Although Ono was a hard-working and dedicated student, he himself had no choice but to change his research topic to the determination of the atomic weight of uranium after tackling with nipponium for one and a half years. Since most of the graduate students chose to study organic chemistry under Majima, Ogawa continued his pursuit for nipponium almost by himself while he was busy as the president of the university from 1919.

Concerning the second period starting in 1925, let us examine how nipponium was treated by chemists in Japan. This was the year when the announcement of the discovery of the elements 43 and 75 by the Noddacks was promptly introduced to chemists in Japan; in his article, Yuji Shibata of Tokyo Imperial University mentioned Ogawa's earlier achievement on the element 43 (Shibata, Y. 1925). Thus, it seems that in Japan it was believed that the Noddacks confirmed that nipponium was actually the 43rd element, but not rhenium. Aoyama was promoted to an associate professor and obtained the opportunity to study in Europe in 1925. He learned X-ray spectroscopy in Bohr's institute in Copenhagen. Although Hevesy had left there for Freiburg before Aoyama's arrival, Aoyama got acquainted with Kimura and Yoshio Nishina there and published a paper together (Aoyama et al. 1927). He also had an opportunity to learn low temperature technique in Kamerlingh Onnes Lab in Leiden before returning to Japan in 1928.

Kimura and Aoyama imported X-ray spectrometers to Japan. The spectrometers became operational by Kimura at Tokyo in 1929 and by Aoyama in Sendai in 1930. As Yoshihara described, both examined Ogawa's nipponium samples in 1930 and independently revealed rhenium as the main component just before Ogawa died. Kimura and Shinoda continued to identify rhenium by extracting it using one $\mathrm{kg}$ of Japanese molybdenite, and presented the results at the monthly meeting of the Chemical Society of Japan (Shinoda 1930).

Curiously, they never published the X-ray results, although Kimura's group actively published a number of papers on the contents of various minerals produced in Japan. Shinoda later told Yoshihara that he had not recognized any relation between Ogawa's nipponium and rhenium mostly because he was often absent from the lab for his health reasons and did not even know that Kimura also examined Ogawa's nipponium sample. According to what Yoshihara heard from Sasaki, who worked for Inoue, an intimate colleague of Kimura, Kimura prepared to publish Shinoda's result of rhenium in molybdenite but decided not to since he learned that by then as much as $120 \mathrm{~kg}$ of rhenium already became available (Meggers 1931b).

In the obituary article Aoyama wrote for Ogawa, he removed the words "Preliminary note" from the title of Ogawa's first paper to make it "New Element in Thorianite", while maintaining these words to list the second paper. In this we speculate Aoyama's confidence 
and intention as an observer of the clear X-ray peak of rhenium in Ogawa's nipponium sample extracted from thorianite (Aoyama 1930).

Until 1925 in Japan, nipponium was widely considered as the 43rd element. However, after Ogawa's death there appeared some reports implying that it was the 75th element rhenium, such as the statements by Aoyama and Otsuka, as described above. In addition, a professor in organic chemistry at Hokkaido Imperial University, Zenichi Shibata, who studied under Ogawa as a student, wrote in a popular science magazine in 1940 about the achievements by Ogawa and the Noddacks (Shibata, Z. 1940). He wrote that Ogawa's name associated with the discoverer of nipponium was forgotten. Then, he proposed to replace Ma for $\mathrm{Np}$ since there were no further reports on the element 43, but at the same time he expressed his wish to fill the position of Re with $\mathrm{Np}$ if possible. He attributed the lack of advanced apparatus in Japan to the reason why Ogawa's name did not remain as a discoverer, and he regretted the unfortunate difference in research environment for Ogawa.

As described in Section "International evaluations", Majima was asked by Tiede in Berlin in 1938 if nipponium was rhenium (Majima 1954). It was in his autobiography that he disclosed this episode. We may speculate that Majima knew about the X-ray results at some early stage and wanted to disclose his long-time concern through the word told by Tiede.

Concerning the third period after Ogawa passed away, his second son Eijiro, after finishing his doctorate study in chemistry at Tohoku Imperial University, moved to Kyushu Imperial University in 1929 to pursue his career as a chemist and started to study ruthenium and rhenium. He obtained his doctor degree in 1933 for his studies on the chemical properties of iridium and ruthenium, and notably of rhenium (Ogawa, E. 1932b). In 1931, Eijiro posted his thoughts on his father's research in the magazine of the alumni association of the Department of Chemistry of Tohoku Imperial University (Ogawa, E. 1932a). Eijiro, familiar with the rarity of rhenium and the hygroscopicity of its oxides, praised the Noddacks' technique but at the same time considered their discovery as a lucky result. Eijiro thus wrote that he wished his father to receive the honor of the discovery. He regretted that the name nipponium had become obsolete and nearly forgotten, then he continues as below. From such description, he must have assumed that nipponium was in fact rhenium.

For nearly 20 years, my father continued to study the new element he discovered, but he relied solely on analytical chemistry without using newly-developed research equipment. The methodology had both strengths and weaknesses. He always insisted on confirming nipponium by chemical analysis since it was discovered by chemical analysis. Such an idea meant a defeat for science which should be conducted with a calm mind. ... Considering how little the target elements are contained, a scientist needs to strive to discover them using the latest and best equipment. My father must have known this well, but his natural competitive spirit did not allow him to take different approaches. Nevertheless, in later years he became keenly aware of the inevitability of the latest equipment, but by that time the situation around him did not allow it (Ogawa, E. 1932a).

Eijiro Ogawa continued to conduct verification experiments on his father's nipponium, while conducting his main research on isotope separation and alloys at Kyushu Imperial University (Yoshihara et al. 2002). Eijiro examined rare elements contained in flue ashes and volatility of elements. In 1944, Eijiro finally extracted an element similar to his father's 
by X-ray and optical spectroscopies. This study was primarily performed by Eijiro himself, but the spectra were measured by his assistant, Misao Kanatani. In a letter to Yoshihara, Kanatani wrote that Eijiro was convinced of the identity of nipponium:

Professor Eijiro Ogawa looked for the element 43, but after he carefully examined an enlarged photographic plate and calculated the expected spectra, he told me that the characteristic peaks did not match with those of the element 43. Were they not the lines for rhenium? I remember he was once examining the anticipated peak locations for rhenium (Yoshihara et al. 2005).

In the early 1940s, Eijiro struggled to place nipponium at the number 43. He died shortly afterwards, grabbing indirect evidence of nipponium, and details of that study were never published.

We add that Hisateru Okuno with a pen name of "Zainshi", wrote on the details of Ogawa's discovery of nipponium in a series of articles on the history of the discovery of elements, although he did not mention a possible relation between nipponium and rhenium (Zainshi 1973).

\section{By Ogawa himself}

In this sub-section Section "By Ogawa himself", we discuss in the viewpoint of Ogawa himself why he was not able to identify nipponium as the 75 th element. The period of our examination is divided into three: First, while he and his colleagues published the papers on nipponium between 1906 and 1912; Second, until the Noddacks reported the new element rhenium in 1925; third, until he died in 1930.

\section{6-1912: during the publications}

Ogawa returned to Japan in 1906, performed additional experiments, and published the three papers on the new elements in 1908-1909. During this period, his mentor, Divers, advised Ogawa to reconsider the valence of the new element nipponium assumed in the papers.

Divers taught Ogawa at the Imperial University of Tokyo and returned to England in 1899, the same year that Ogawa became a professor at the First High School, a three-year liberal arts college in Tokyo (Haga 1912). While he was in Ramsay's lab at UCL, Divers took a close and parental care of him, inviting him home on weekends, and discussed the progress of his research (Yomiuri Shimbun Newspaper 1912). When his first paper on nipponium was drafted, he sent a copy to Divers as well as Ramsay (Kikuchi 2004). It should be noted that Divers directly inquired Ramsay and Ogawa on their views on the placement of nipponium in the periodic table. He proposed that higher oxides and their salts be synthesized to solve the problem concerning the position in the periodic table. Divers even wrote to Joji Sakurai, the president of the Chemical Society of Japan about his concern (Kikuchi 2004).

However, in the first paper, Ogawa assumed a divalent state and just pointed out the existence of an oxide with hexavalent nipponium, without reporting its details. He insisted on the divalent states of nipponium without showing its evidence nor rationale, and derived 
the atomic weight of 100. Divers' criticism was rather reasonable, since even in the periodic table known that day, the element 43 is neighbored by manganese, molybdenum, and ruthenium, all known to have higher valences than two. Why did he not follow Divers' advice? He strongly respected Ramsay's foresight and held long discussions with him at UCL, so that he might have been unconditionally convinced that nipponium was the element 43 (Ogawa 1912). One possible reason for his insistence on the divalency was that it led to the atomic weight of 100, consistent with the 43rd element. Had Ogawa followed Divers' advice more seriously, he might have been able to find out that nipponium with higher valency would have resulted in the element 75 instead, even from his analytical experiments alone. He seemed to have been aware that his first paper contained preliminary contents. In fact, he mentioned in the abstract of the paper that the study was preliminary and to be continued. Additional experiments to examine Divers' advice must have been planned, but never published.

By 1907 Ogawa obtained nipponium metal samples from both electrolysis and reduction by hydrogen, and displayed them at the exhibition of the Three Society Associations (Chemistry, Mathematical and Physics, and Electrical Engineering) (Ogawa 1907).

\section{3-1925: before the report by the Noddacks}

Ogawa missed the correct assignment during his publication of the three discovery papers. Was there a chance for him to identify $\mathrm{Np}$ as the 75th element before the Noddacks reported it in 1925? Since the discovery of Moseley's law in 1913, it had become essential to use X-ray spectra for the identification of the new elements. Naturally a question arises why he did not get his nipponium samples examined by X-ray as soon as he had any opportunity. Then, he might have identified nipponium as the 75th element as its discoverer before the Noddacks. That would have revealed his incorrect assignment of nipponium as the 43rd element, but the prestige as the discoverer of the 75 th element would not have damaged Ogawa's fame.

He continued his research on nipponium after the publication of the three papers. In the spring of 1913, he exhibited nipponium samples extracted from thorianite at Tohoku Imperial University, and even the president, faculty members of physics and mathematics, as well as students came to see Ogawa's findings. He reported on nipponium research at the Chemical Society of Tokyo in 1911 and 1917 (Ogawa 1911, 1917), both of which were on thorianite. In the 1917 report, he implied to shift his study from thorianite to platiniferous minerals, since the former contained exceedingly small amounts of nipponium while the latter contained elements with similar properties to nipponium.

It became known later that molybdenite contains abundant rhenium. Although Ogawa reported in the first paper that molybdenite from Japan also contained nipponium, he soon stopped using molybdenite and continued to concentrate on thorianite. This is perhaps because Ogawa's method of extracting new elements by precipitation of hydroxides in ammonia solution was not suited for nipponium contained in molybdenite. He did not report any analyses of molybdenite after the third paper. Perhaps nipponium was detected in the emission spectrum of the samples from molybdenite, but he could not find a way to isolate it in the form of a pure nipponium compound. During this period, he also conducted experiments to obtain higher oxidation states of nipponium, as advised by Divers. 
As pointed out by his son Eijiro, it is more difficult to handle nipponium oxide with higher valence (Ogawa, E. 1932b). In our present knowledge, a higher-valency rhenium oxide would be $\mathrm{Re}_{2} \mathrm{O}_{7}$, unstable in air (Fig. 4).

By this time, Ogawa became the first dean of the College of Science of Tohoku Imperial University. Still eager to continue the experiment, he set up a bed in the laboratory and conducted the experiment late at night, sometimes all night. Later, one lecture room was renovated into the dean's office and an inorganic chemistry laboratory next to each other, so that the research could be conducted immediately after the daily dean's duties. Since there were no students nor staff members in his lab between 1916 and 1918, the nipponium research had to be conducted alone. The 1913 issue of the Tohoku Imperial University bulletin described that Professor Ogawa was enthusiastically continuing his research on the new element nipponium.

Perhaps, it was not possible for Ogawa during World War I (1914-1918) to send the nipponium sample to Europe for the examination by X-ray. As soon as the war was over, he planned a scholarly tour in the fall of 1919 to Europe and the United States (Kahoku Shimpō Newspaper 1919a). However, in June of that year, the president of Tohoku Imperial University was decided by an election on campus for the first time, and he was recommended and elected (Kahoku Shimpō Newspaper 1919b). Ogawa had to accept the appointment as the president and the overseas tour was canceled.

Soji Makita, a classmate with Ono and a researcher at a steel company in Hokkaido, had a conversation with Ogawa about nipponium samples in the brand-new president's office in the fall of 1919 (Makita 1930).

Professor Ogawa showed me a lump of silvery metal, one cubic centimeter in size, in

the president's office and said "The new element is in it. I will proceed with the X-ray

analysis."

Such a metal lump might have been a collection of materials he had obtained by electrolysis. It is deduced from this conversation that Ogawa intended another tour after a while. In the meantime, there was no X-ray spectrometer available to him in Japan. Contrary to his hope, however, the workload as the president of newly developing Tohoku Imperial University was too heavy to allow him to visit abroad. Despite his dedicated efforts, Ogawa himself could not publish any further results on nipponium. In February 1925, a newspaper reported that research on nipponium was at last in its final stage. It was scheduled to be announced at the end of March, but it was subsequently reported to be delayed (Kahoku Shimpō Newspaper 1925b). Since then, Ogawa had never made any positive announcements.

In March 1925, Ogawa dispatched his assistant Aoyama to Europe to learn the X-ray as well as cryogenic techniques. This would have been an ideal opportunity for Ogawa to identify the atomic number of the element nipponium. However, he did not have Aoyama take the nipponium sample to Europe. We can only speculate the reason; he might want to examine it either by himself or at least in Japan, since it was planned that Aoyama soon introduced the X-ray spectrometer to Japan after coming back to Japan in 1928. As a developing country in science, it must have meant a lot if a new element is discovered and identified entirely in Japan. 


\section{5-1930: after the report by the Noddacks}

It was in June 1925 that Noddack, Tacke, and Berg reported their discoveries of two new elements, masurium Ma with the atomic number 43 and rhenium Re with 75, from molybdenite (Noddack et al. 1925). As we presented in Fig. 5, the precise optical emission spectrum of rhenium became available only in 1931 (Meggers 1931a) and it well reproduced the features reported by Ogawa in 1908. If he had published a detailed optical spectrum of nipponium after the brief description in the first paper, nipponium would have been identified as rhenium in the international community much earlier. It does not seem that Ogawa considered to identify rhenium discovered by the Noddacks to nipponium. On the contrary, their report of the 43rd element might have encouraged Ogawa to continue his pursuit of reproducing his discovery of nipponium as the 43rd element.

Japanese historian of chemistry Masanori Kaji analyzed Ogawa's limitation as follows:

One must point out at the same time that Ogawa did not have the frame of mind to organize a project-type research group, confining himself instead to individual research. This attitude did not help to advance his work fast enough. If he were a researcher of today, it would be unthinkable not to publish anything after his preliminary report in 1908, even though he continued to study his "nipponium." He should have published something (Kaji 2015).

As described in the previous subsection and in Fig. 6, it was actually only just before Ogawa's death in 1930 that the X-ray spectrometer finally became operational in Sendai and recorded the clear spectral peaks of rhenium from the nipponium sample.

\section{Conclusions}

We have reexamined the works by Ogawa and Yoshihara and concluded that they provide indisputable evidence that Ogawa's nipponium is re-assigned to the 75th element, named rhenium seventeen years later. Ogawa himself believed that nipponium was the element 43, later known as the unstable radioactive element technetium (Tc).

The core of the indisputable evidence consists of (1) the weight changes reported by Ogawa, after interpreted with the actual chemical reaction processes, lead to the correct atomic weight of rhenium, (2) the optical emission spectra described by Ogawa are consistent with that of rhenium, and (3) the X-ray photographic plate for a nipponium sample shows clear peaks of rhenium.

We have made critical evaluation of Yoshihara's achievements. Concerning (1), our revised assignments of the chemical reactions summarized in Table 2 does not affect Yoshihara's main conclusion. Concerning (2), we emphasize that Ogawa described the previously-unknown optical spectra. This is essentially different from reports claiming new elements based on their X-ray spectra after the "correct answer" became known beforehand from Moseley's law. Regarding (3), we revised the peak assignments on Aoyama's X-ray photographic plate as shown in Fig. 6 and Table 4, which substantially improved the fitting and reassured that the nipponium sample contained strong peaks of rhenium. 
We explained how Ogawa's work was often incorrectly cited and we attributed such misunderstanding to the fact that he published some key results only in Japanese. By examining the details of such miscommunications, we tried to answer many of the questions concerning Ogawa's discovery.

Based on a number of historical resources, we extended our evaluation of Ogawa's strength and weakness as a scientist who searches for and identifies a new element. Ogawa's strength was his superb ability to extract minute element contents from the minerals by traditional wet-chemistry processes. As his weakness, he insisted on such an approach alone and did not organize a team with multiple expertise necessary to identify new elements. It must have been Ogawa's insistence to search for the 43rd element that prevented him from reconsidering the re-assignment as the 75th element perhaps until just before his death in 1930. As a remaining question, at least a few chemists who most probably knew that nipponium was rhenium never published such results even after Ogawa's death. It is easy to say that the science in Japan was not matured enough, but considering the imperial fame Ogawa received, it must have been difficult to disclose the unwanted truth in that period in Japan.

The issue of identifying nipponium had been fading away until Yoshihara shed light on Ogawa's work. We hope Ogawa's discovery of nipponium receives proper evaluation internationally, based on the facts described here.

\section{Appendix A}

This Appendix consists of the figures (Figs. 7, 8, 9, 10, 11, 12) based on Ogawa's papers.

In Ogawa's three papers (1908a, 1908b, 1909), he described the chemical extraction processes only in sentences. Figures $7,8,9,10,11,12$ below represent diagrams to show the full details of the processes he used.

Figure 7: The improved separation scheme adopted after Ogawa came back to Japan for extracting nipponium from thorianite (1908a, 1909). The hydroxide obtained in this scheme constitutes a basis for the characterization of nipponium compounds shown in the diagram in Fig. 2.

Figure 8: Separation scheme for nipponium from reinite and molybdenite (1908a).

Figure 9: Process scheme to obtain a new element candidate allied to molybdenum (1908b).

Figure 10: Process scheme to treat the zirconium-silicate impurity phase attached to thorianite. Ogawa initially thought that this impurity contained a substantial amount of nipponium (1908b), but immediately corrected this error (1909). He recognized a small amount of an element not separable from zirconium, possibly hafnium, but was not able to characterize its properties.

Figure 11: Simplified diagram for the separation scheme Ogawa used at UCL (1909). Ogawa obtained a strong evidence for a new element A contained in alum.

Figure 12: Full details of the separation scheme Ogawa used at UCL (1909). Note that $1.5 \mathrm{~kg}$ of the starting $\mathrm{H}_{2} \mathrm{~S}$ precipitate Ogawa used was only a small portion of the preprocessed material from $250 \mathrm{~kg}$ of thorianite. 


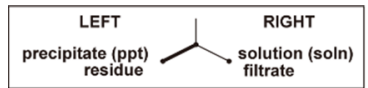

Finely powdered Thorianite $1 \mathrm{~kg}$

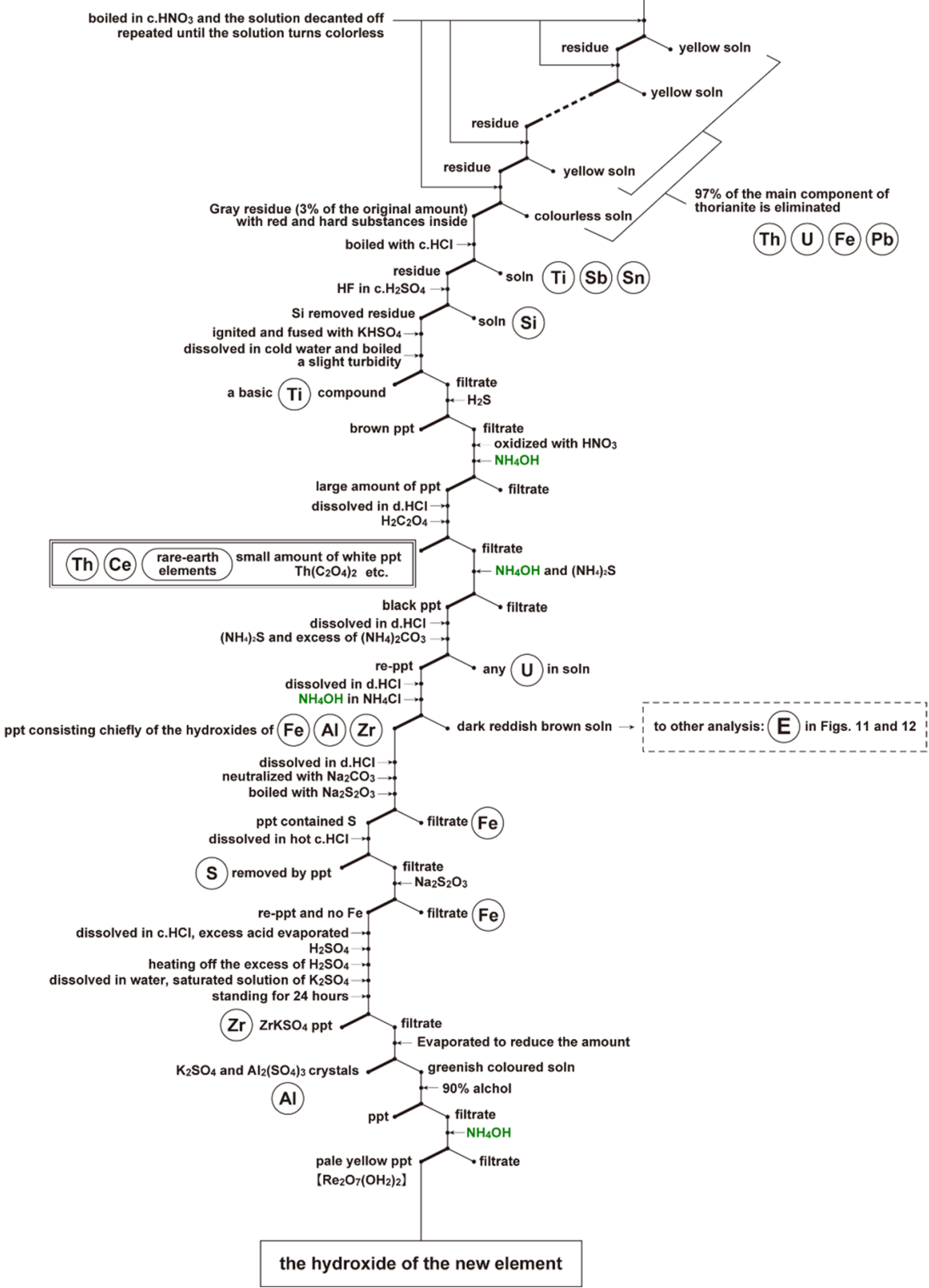

Fig. 7 Improved separation scheme for nipponium from thorianite in Japan. This figure represents the improved chemical process described in the first and third papers (Ogawa 1908a, 1909) to extract nipponium hydroxide from the thorianite mineral Ogawa brought from UK to Japan. The hydroxide product was used for the characterization of nipponium reported in the first paper. Ammonium hydroxide $\mathrm{NH}_{4} \mathrm{OH}$ is highlighted in green to show his main scheme of ammonia precipitation. The X-ray spectrum by Aoyama was most probably obtained using the sample processed in this way 


\begin{tabular}{|c|c|}
\hline LEFT & RIGHT \\
$\begin{array}{c}\text { precipitate (ppt) } \\
\text { residue }\end{array}$ & $\begin{array}{c}\text { solution (soln) } \\
\text { filtrate }\end{array}$ \\
\hline
\end{tabular}

\section{(a) Reinite Process}

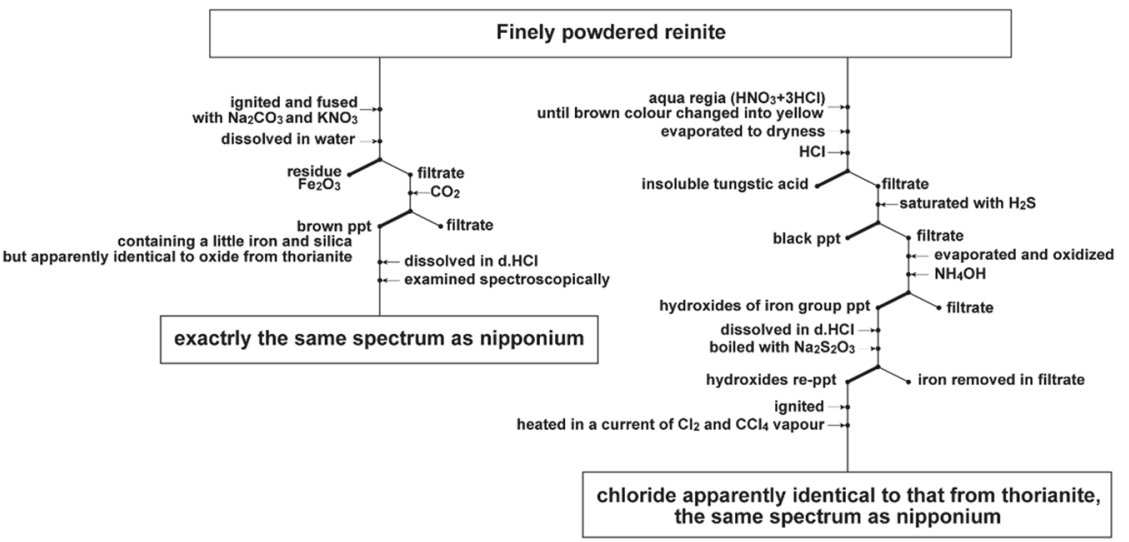

\section{(b) Molybdenite Process}

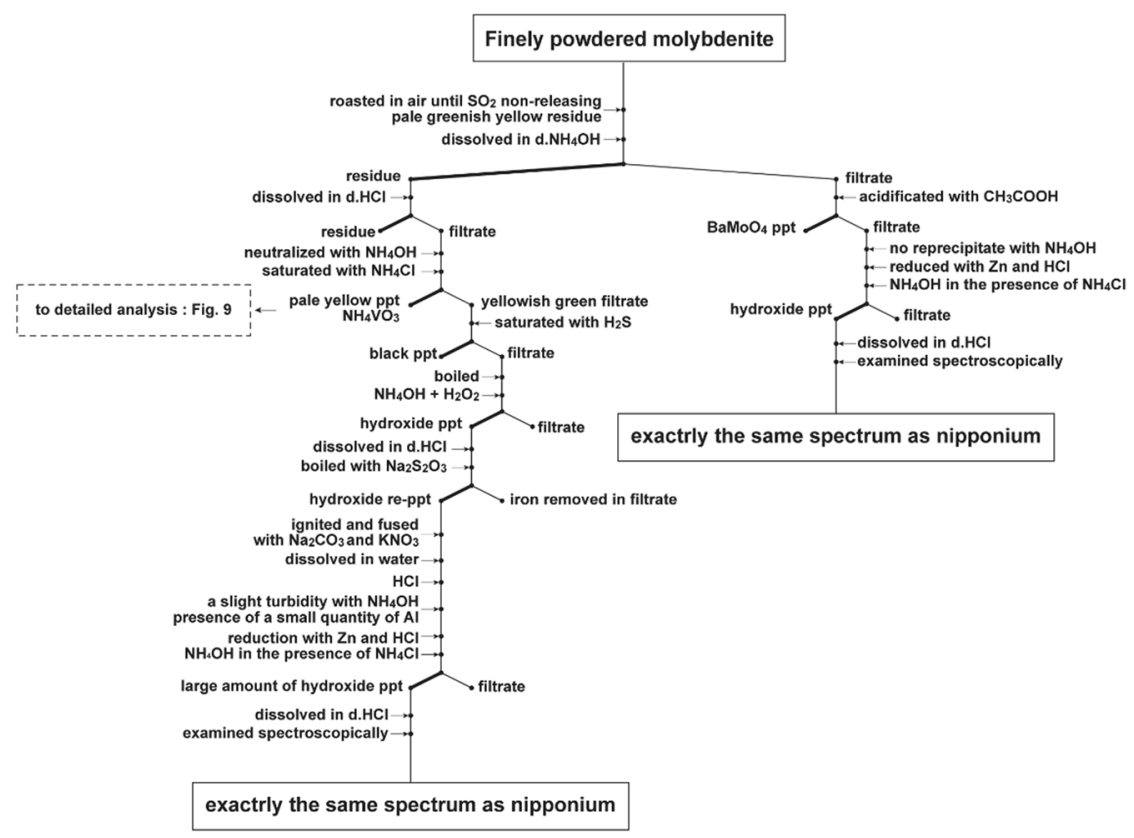

Fig. 8 Ogawa's separation schemes for $\mathbf{a}$ reinite and $\mathbf{b}$ molybdenite reported in the first paper (Ogawa 1908a). Since Ogawa had concerns about the ammonium vanadate filtered by the left route in (b), he examined the precipitation in detail and found a new element allied to molybdenum in molybdenite, as shown in Fig. 9 


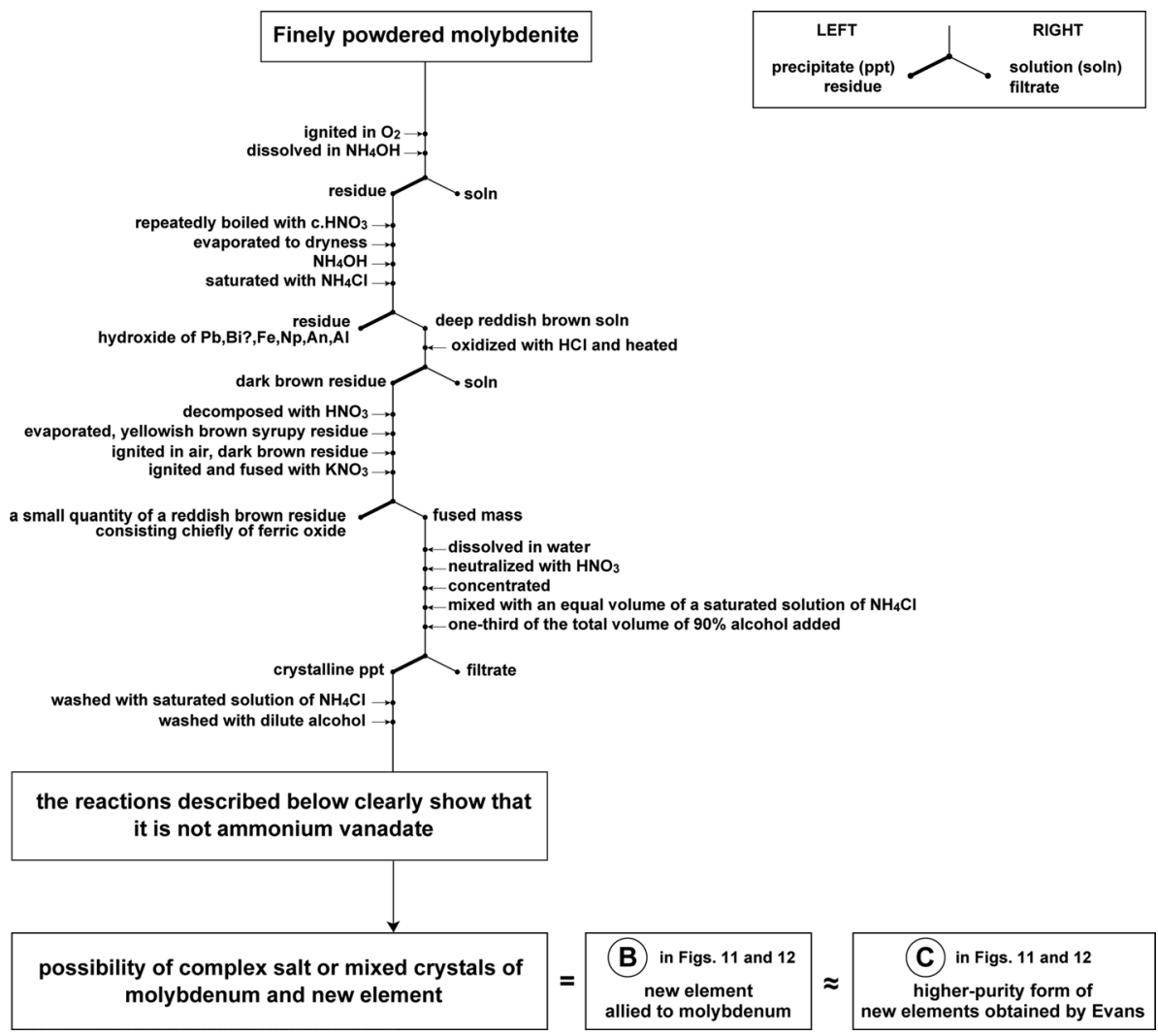

Fig. 9 Process scheme to extract the ammonium salt of an unknown element in molybdenite. This chart represents the route to obtain an ammonium salt with properties similar but distinct from those of molybdenum reported in the second paper (Ogawa, 1908b). Ogawa extracted a metal from this salt by electrolysis and examined its properties, but only obtained an equivalent value of 16.7, pending determination of the atomic weight. Ogawa concluded that this new element was the same as the new element B in Figs. 11 and 12 , and was consistent with the higher purity form of the new element $\mathrm{C}$, which was considered as the same element discovered by Evans 


\begin{tabular}{|c|c|}
\hline LEFT & \multicolumn{1}{|c|}{ RIGHT } \\
$\begin{array}{c}\text { precipitate (ppt) } \\
\text { residue }\end{array}$ & $\begin{array}{l}\text { solution (soln) } \\
\text { filtrate }\end{array}$ \\
\hline
\end{tabular}

Finely powdered zircon

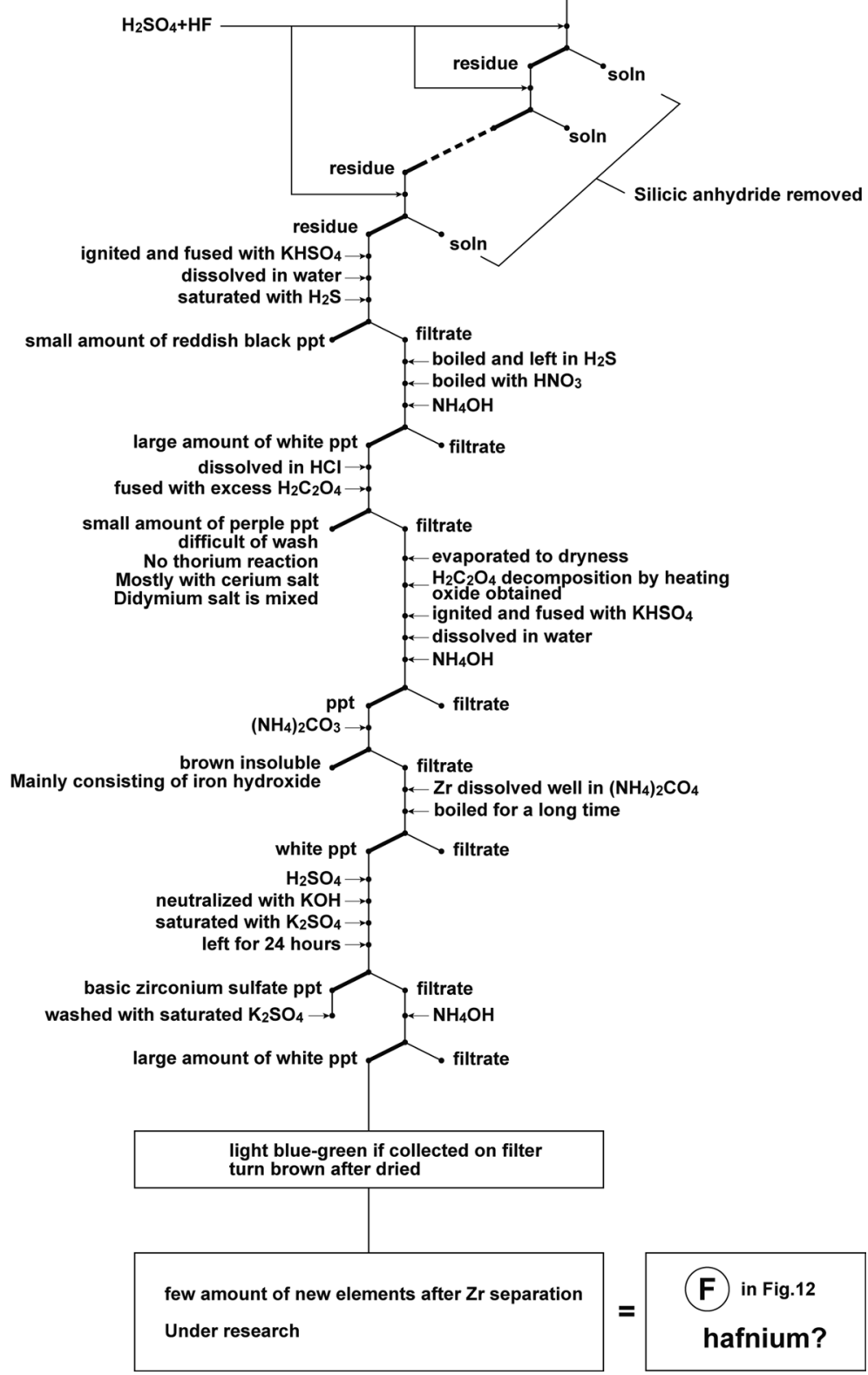

Fig. 10 Process scheme for zirconium-oxide-like minerals attached to thorianite. This chart represents the details of the process shown in Fig. 12 to reach F. A complex silicate of zirconium and an unknown element was obtained. Ogawa initially thought that this unknown element had properties similar to those of nipponium, and announced it as an abundant source of nipponium in the second paper (Ogawa 1908b). However, he denied this result in the third paper (Ogawa 1909) and described that it contained little nipponium. Nevertheless, it contained a new element inseparable from zirconium; Ogawa might have seen traces of hafnium 


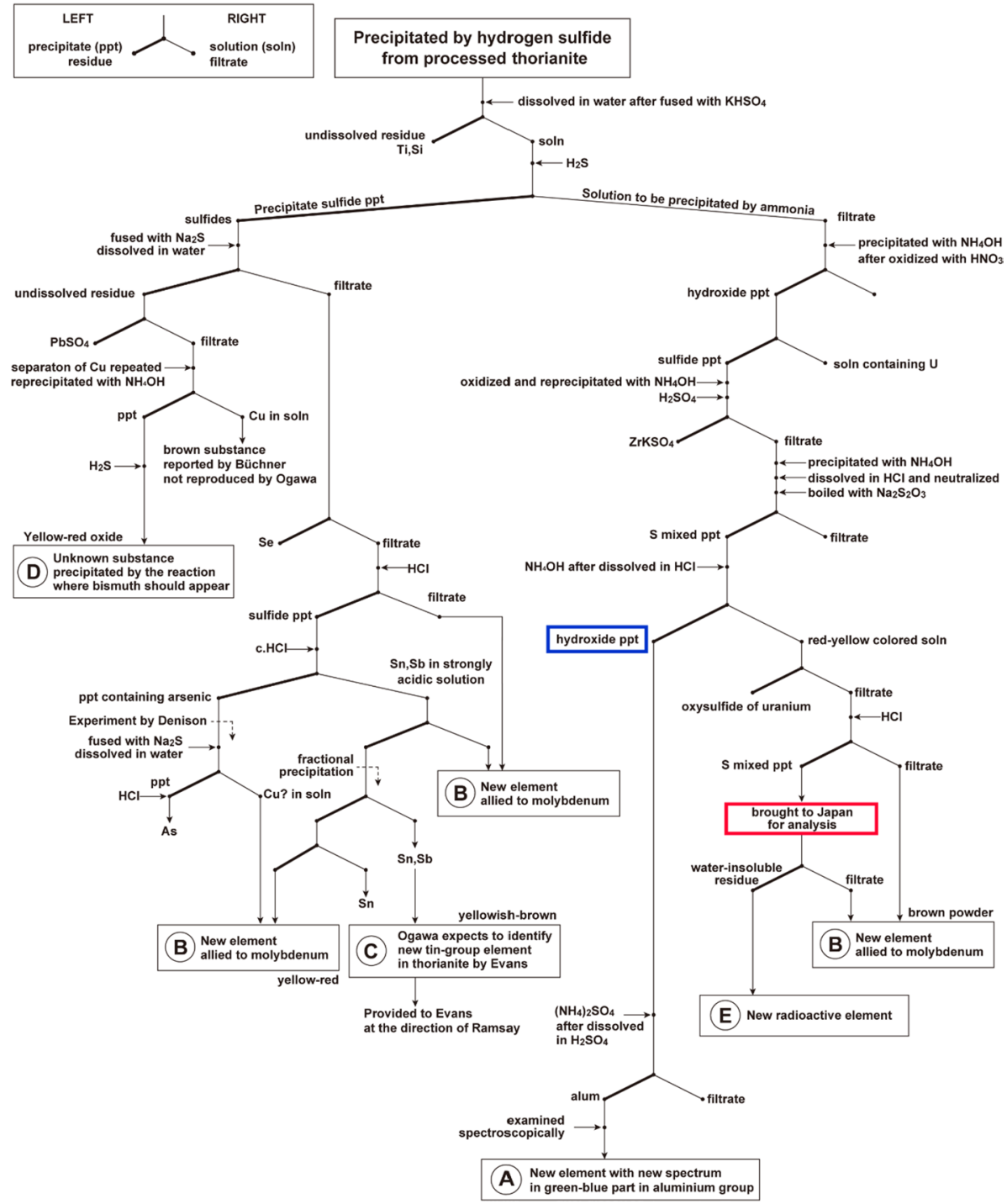

Fig. 11 Summary of Ogawa's separation scheme for thorianite at UCL. Chemical processes Ogawa used to extract new elements from hydrogen sulfide precipitates of thorianite while he was at UCL. This figure summarizes the outline of the processes, while Fig. 12 shows the details. Among the new element candidates, A to F, A was named "nipponium" for which the optical emission spectrum was reported. E in the lower right-hand corner is the result obtained in Japan after Ogawa brought the sample from UCL. The hydroxide shown in the blue box as well as the sulfur-containing precipitate shown in the red box were used in Ogawa's investigations in Japan 


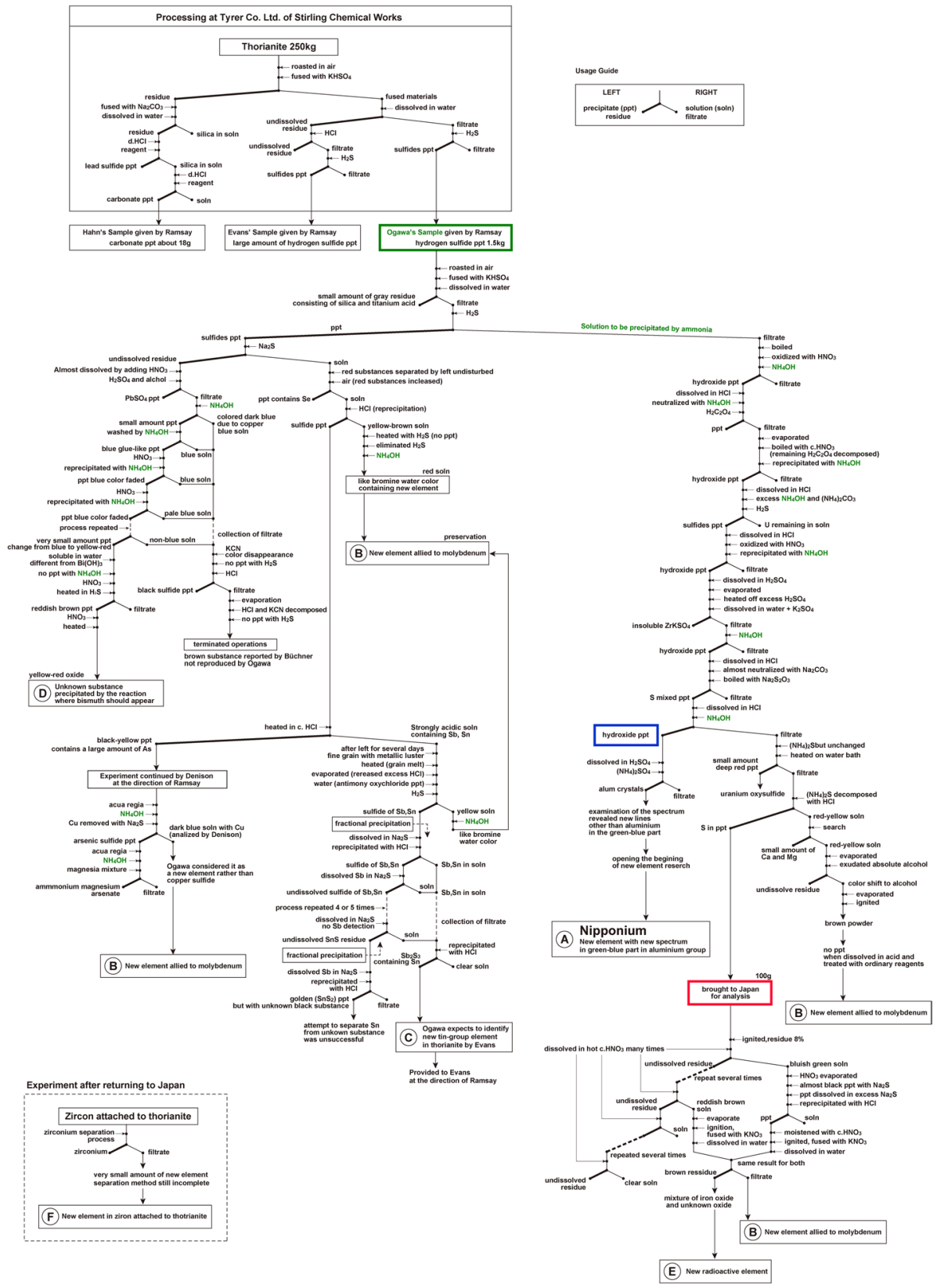

Fig. 12 Details of Ogawa's separation scheme for thorianite at UCL, reported in the third paper (Ogawa 1909). F at the lower left concerns the zircon-like minerals attached to thorianite that Ogawa analyzed in Japan; the details of extracting $\mathrm{F}$ is shown in Fig. 10. Table 1 in the main text summarizes all the new element candidates A to F reported by Ogawa, as well as their modern interpretations. The green box at the top indicates that Ogawa analyzed only a part of the pre-processed thorianite minerals of $250 \mathrm{~kg}$. The hydroxide shown in the blue box as well as the sulfur-containing precipitate shown in the red box were used in Ogawa's investigations in Japan. Ammonium hydroxide $\mathrm{NH}_{4} \mathrm{OH}$ is highlighted in green to show his main scheme of ammonia precipitation 


\section{Appendix B}

The following is the full translation of Yoshihara's counterarguments on Scerri's view with our notes added. The publication of this material has been approved by the Japanese Society for the History of Chemistry as well as by Yoshihara.

\section{On Nipponium - Revisiting Eric Scerri's View -}

\section{Kenji Yoshihara.}

(Received: March 23, 2015).

The Journal of the Japanese Society for the History of Chemistry (Kagakushi) 42 (2015) 206-209.

This column is not a book review. The purpose is to correct misunderstandings on nipponium in the book published by Eric Scerri of the University of California, Los Angeles.

Nipponium is an element ${ }^{1,2)}$ reported by Masataka Ogawa in 1908; it is not listed on the periodic table at present. This element was allotted to fill the vacancy between molybdenum and ruthenium in the periodic table by Ogawa, with the support of the great British chemist William Ramsay (the Nobel Laureate in Chemistry in 1904 for the discovery of noble gases). It was once highly evaluated as a new element and was adopted in Loring's periodic table ${ }^{3)}$. However, it could not be confirmed by further studies, and it was later replaced by the radioactive 43rd element technetium ${ }^{4}$.

When both nipponium and Ogawa were almost completely forgotten, the symposium "Discovery of the Elements" was held in Belgium in 1996. At the invitation of the committee, I reported that nipponium was not the 43rd element but can be considered as the 75th element rhenium, which is one period lower on the periodic table. It was published in Radiochimica Acta $^{5}$ ) and received a lot of attention. The biggest one was a letter from Prof. Paul Kazuo Kuroda, known for the prediction of natural nuclear reactors, and he said, "It deserves an academic award." (Paul Kazuo Kuroda, Private communication, 1997; Kenji Yoshihara, Scientists' Serendipity: Roads to Nobel Prizes, Tohoku University Press, 2006).

I further investigated Masataka Ogawa's relics. Various items were kept by his fourth son, Professor Shiro Ogawa of Tohoku University ${ }^{6}$. Among the relics, the strongest evidence was the photographic plate found in Shiro's house. This plate was the X-ray spectroscopic photograph taken by Shin'ichi Aoyama, Masataka Ogawa's disciple (Fig. 1: Fig. 13 in the present paper).

The photographic plate is shown in Fig. 1. The characters "Kinken" [Note 1] are written, and the letters of "Coil 1, 2, 3, 4, 5, 6, 8" match Aoyama's handwriting. "Coil" means a coiled periodic table ${ }^{7)}$ shown in Fig. 2 (Fig. 14 in the present paper), which is wound like a decoration. In Bohr's laboratory, where Aoyama studied abroad, such a playful and fun periodic table was used. Number 7 is missing from the number sequence. If we read that the numbers are the group numbers of the elements in the periodic table.

$1(\mathrm{Rb}), 2(\mathrm{Sr}), 3(\mathrm{Y}), 4(\mathrm{Zr}), 5(\mathrm{Nb}), 6(\mathrm{Mo}), 8(\mathrm{Ru})$,

number 7 is technetium, the element that is rarely found in nature, and was excluded because it is not used as a standard. In short, Aoyama compared Ogawa's nipponium with the standard elements so that it could be easily explained to Ogawa.

If Ogawa's sample contained the element 43, there should be a peak between molybdenum and ruthenium. Since the spectrum is complicated, it is better to compare the K $\beta$ lines. As a result, there is no corresponding line there. Instead, two sharp lines appeared on the left 


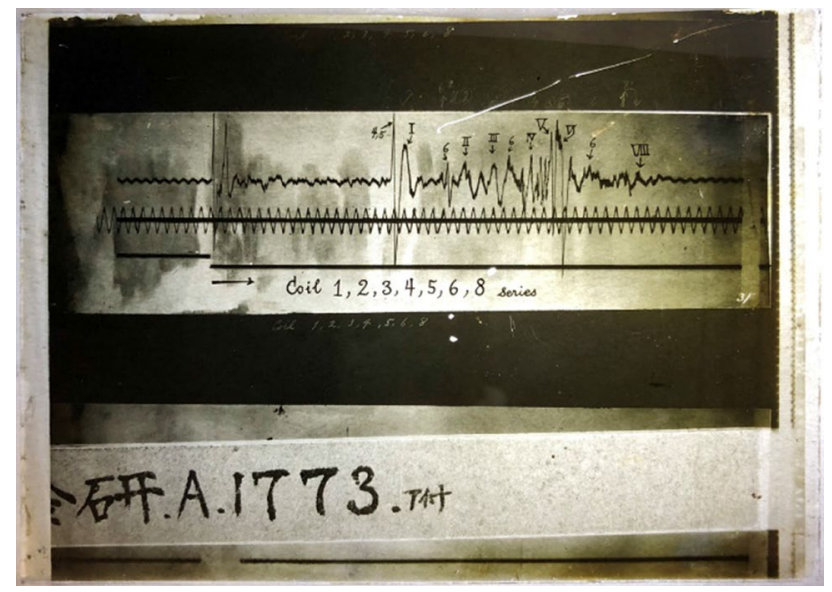

Fig. 13 (Fig. 1 in Yoshihara (2015)) Spectral analysis photographic plate from Masataka Ogawa's relics (Tohoku University Archives)

Fig. 14 (Fig. 2 in Yoshihara (2015)) The right half of the coiled periodic table. Taken from Ruth Moore ${ }^{7)}$

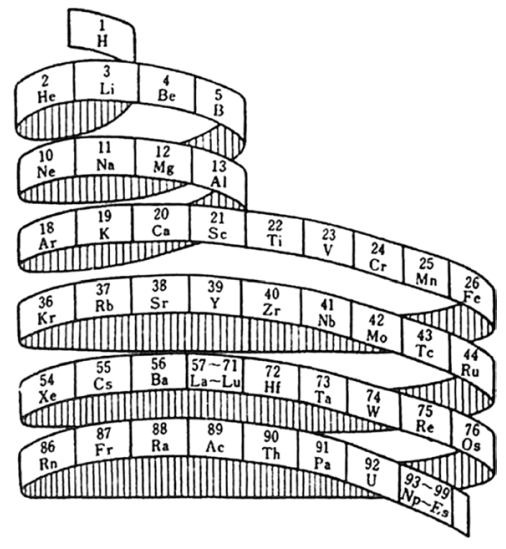

side. While no explanation was written on the photographic plate, my analysis resulted in rhenium L $\beta 1$ and L $\beta 2^{8}{ }^{8}$. Ogawa went to his alma mater, the Department of Chemistry at the University of Tokyo, and asked up-and-coming chemist Kenjiro Kimura to measure the same sample with the same type of an X-ray analyzer (1930). It was "a beautiful rhenium," said Kenjiro Kimura9). Ogawa was said to have returned disappointed (Rhenium had already been discovered by the Noddacks in 1925). This was not announced, and Ogawa soon became ill in his laboratory and died eight days later at Tohoku University Hospital. It was July 11, 1930. The results of my decoding of the photographic plate are consistent with Kimura's words. The photographic plate was a solid proof that nipponium was rhenium.

As described above, it became certain that nipponium is consistent with rhenium from the evidences of optical and X-ray spectra and from the existence of rhenium in molybdenite, and Masataka Ogawa's nipponium has been widely re-evaluated.

However, as mentioned above, Professor Eric Scerri, a professor of philosophy and history of chemistry at the University of California, Los Angeles, published A Tale of Seven Elements in $2013^{10}$ ), in which he challenged that nipponium was rhenium. I read the book 
and found many mistakes and assumptions, and he develops his own theory on these. I wondered if I could ignore it, but I came to the conclusion that I should refute what was wrong scientifically. Recently, there have been situations in which the ethics of scientists are being questioned. I refute for the honor of the Japanese Society for the History of Chemistry [Note 2] and want to keep readers from being confused by this book.

\section{About A Tale of Seven Elements}

Especially in the section on nipponium in Chapter 5.

[1] There are quite a few descriptive mistakes.

Page 110, line 10.

Although it says "Ogawa moved from the University of Tokyo to Sendai University," he actually moved from the Tokyo Higher Normal School to Tohoku Imperial University [Note 3].

Page 112, line 6.

"Then, in 1927, Kenjiro Kimura purchased an adequate X-ray spectrometer and indeed attempted to verify Ogawa's new element."

The latter half of this sentence can be taken as if Kenjiro Kimura actively began to identify nipponium. That was not the case. Kimura was asked by Ogawa to measure it with an X-ray spectrometer. He did not have an intention to take credit for himself actively.

Caption of Fig. 5.5 on page 113.

"X-ray peaks from Kimura's experiments".

Correctly, this is the X-ray spectrum which Aoyama measured at the request of Ogawa. It also contradicts what was written on the previous page.

[2] The sentences on page 112 on line 21 and what follows are a complete misunderstanding in an important point. That is, the upper curve in Fig. 5.5 was taken by Aoyama, and the lower curve is the one with modern standard values for easy understanding. Eric says that (the forms of) both do not "consist" [Note 4] because he does not understand the essence of the problem. The important issue here is not the shape but whether the peak positions match. The difference in shape is not the problem. In the Siegbahn-type spectrometer, a film is placed on a Roland circle, exposed to X-rays, and the degree of blackening is measured with an attached meter. The standard sample is often measured separately from the measurement sample. Both films may be overlaid later and compared. The synthesized spectrum can be compared with the standard for elemental analysis of the sample. This is elementary in X-ray spectroscopic analysis. This type of device is not used at present, but it is a common knowledge in spectroscopic experiments. Eric describes his theory on misunderstandings.

[3] Page 113, line 4 and the sentences that follows.

This is also a problem. These sentences criticize what I said about the atmosphere at Japanese universities before World War II. I suggested that it was due to a Japanese seniorjunior relationship that Kimura did not tell anything to others (except his best friend Inoue) after conducting the X-ray analysis of the nipponium sample given by Ogawa and knowing that it was rhenium. It was considered not good to point out the mistakes of seniors 
at universities during the prewar period. It would have been even more so for Kimura, who was a descendant of a samurai family of the Tsugaru clan and was a Christian. Inazo Nitobe [Note 5] described the Bushido spirit in his writing, and I think that Kimura had something close to it. I studied radiochemistry under Kimura. Many people, not just me, admired Kimura's personality. I have to say that it is nothing but Eric's misguided speculation to think about Kimura's feelings without knowing about Kimura.

[4] From the end of page 113 to page 114 , line 9.

He said that the reason that Kimura did not tell others that nipponium was rhenium was because he was not confident and had insufficient evidence. But it is a groundless guess. It was time to determine new elements by X-ray analysis from the 1920s. Kimura studied under Hevesy (the Nobel Laureate in Chemistry in 1943) in Copenhagen and was familiar with the achievement of discovery of hafnium. Hideo Yamadera, an emeritus professor at Nagoya University, admired Kimura's keen experimental sensibility. In the study of hot springs, Yamadera thought that an X-ray line was francium's and so did Paul Kazuo Kuroda, but it turned out that it was the bromine's line as clarified by Kimura ${ }^{11)}$. It can be said that Kimura, who corrected what was scientifically incorrect, was fair. Kimura stopped investigating nipponium not because he was not confident but because he hated to make a rough search for his senior Ogawa shortly after his death. It may be a kind of Kimura's aesthetic. We cannot further discuss what Kimura did not say. As a person who was in contact with Kimura for many years, I have great doubts about Eric's speculations. I have no intention of nepotism at all. Anyone who knows Kimura would well understand that.

[5] Section of "An Attempt to Rehabilitate Nipponium" from page 109, line 5.

As a scientist, I sought the truth about nipponium. The truth comes first, not for the rehabilitation as Eric argued. Rehabilitation is a result and should not be mistaken for an original purpose. It was clear from Majima's oral evidence ${ }^{12)}$ documented in Japanese that what Hevesy obtained as a sample of nipponium was a strange one. Its acquisition route was certainly strange.

Ogawa himself denied it. But Eric, who has not seen this, misunderstands it. He writes as if Yoshihara were obsessed with nationalism. Again, I have patriotism, of course, but science has priority in science. Ramsay, his supervisor in the United Kingdom, acknowledged that Ogawa's analytical skills were outstanding. Is it possible to obtain a final sample containing zirconium as the main component after separating zirconium during the nipponium treatment process? It is impossible. I have to say that Eric's thinking circuit is something wrong.

The contents on nipponium in Eric's book cannot be overlooked because it spreads the misunderstanding of nipponium both scientifically and as the history of chemistry. This is the purpose that I refute here.

\section{Notes by Yoshihara}

(1) Ogawa, M.: Preliminary Note on a New Element in Thorianite. Chem. News 98, 249251 (1908). Ogawa reported the discovery of nipponium with the support of Ramsay. The same content was published in J. Coll. Sci. Imp. Univ. Tokyo 25, Art. 15, 1-11 (1908). 
(2) Ogawa, M.: Preliminary Note on a New Element allied to Molybdenum. Chem. News 98, 261-264 (1908)

(3) Loring, F.H.: The Atomic Weights as Mathematical Functions. Chem. News 100, 281-287 (1909). Nipponium was included in this periodic table with the symbol Np.

(4) Perrier, C., Segré, E.: Some Chemical Properties of Element 43. J. Chem. Phys. 5, 712-716 (1937). Segré et al. discovered technetium made from molybdenum artificially by the cyclotron of Lawrence in the United States. This is a successful prediction as a physicist.

(5) Yoshihara, H.K.: Nipponium, the Element Ascribable to Rhenium from the Modern Chemical Viewpoint. Radiochim. Acta 77, 9-13 (1997)

(6) Yoshihara, H.K., Nakai, I., Terada, Y., Kaji, M.: Studies of Nipponium by Masataka Ogawa and His Son Eijiro. J. Jpn. Soc. Hist. Chem. (KAGAKUSHI) 29, 209-221 (2002) (in Japanese)

(7) Moore, R.E.: Niels Bohr: The Man, His Science, and the World They Changed, trans. Fujioka, Y. Kawade Shobo (1968), 88-89. Biography of Bohr (the Nobel Laureate in Physics in 1922), a Danish scientist who was representative in the 20th century as well as Einstein. Yoshio Nishina, Kenjiro Kimura, and Shin'ichi Aoyama studied abroad at Bohr's Institute in Copenhagen.

(8) Yoshihara, K.: Masataka Ogawa and His Students at Tohoku Imperial University: Research of Platinum Group Elements and X-Ray Spectroscopy. J. Jpn. Soc. Hist. Chem. (KAGAKUSHI) 30, 69-83 (2003) (in Japanese). The carriers and studies of Ogawa's students, Shin'ichi Aoyama and Saichiro Nagami, are shown. In particular, the decoding of the X-ray photographic plate measured by Aoyama at the request of Ogawa was first described.

(9) Yoshihara, H.K.: Ogawa's discovery of Nipponium and Its re-evaluation. Hist. Scientiarum 9, 257-269 (2000)

(10) Scerri, E.: A Tale of Seven Elements. Oxford University Press, New York (2013)

(11) Editorial Committee of the Memorial Magazine of Professor Kenjiro Kimura. Distant Mountains: Kenjiro Kimura and his Era. Private Edition, 268-271 (1990)

(12) Majima, T.: Impressions on the travel in Western countries. Memoirs of Alma Mater of Tohoku Chemistry Department 2, 1-7 (1925) (in Japanese). Majima traveled to Copenhagen for an international conference in 1924. At that time he met Hevesy and was shown a so-called sample of nipponium. After returning to Japan, when he told the story to Ogawa, Ogawa asserted that Hevesy's sample was something he did not remember. It seems that something Ogawa left in London was handed over to Hevesy due to the misunderstanding of a mediator.

\section{Notes added by the authors of the present paper}

1. The characters at the bottom read "Metal Research", the abbreviation for the Research Institute for Iron, Steel, and Other Metals, which was later renamed to the Institute for Materials Research.

2. This column was published in the Journal of the Japanese Society for the History of Chemistry (KAGAKUSHI).

3. Tohoku Imperial University was in the city of Sendai.

4. This is in response to the following statement in Scerri's book: 
"First of all, the two curves do not consist of the X-ray lines obtained by Aoyama and those obtained on "real" rhenium as one would have hoped for. They are a comparison of Aoyama's peaks with the peaks calculated for rhenium."

Yoshihara may have confusion between the words "consist of" and "consistent". He thought that Scerri was pointing out the difference (inconsistencies) in shapes of the peaks between the data and the simulation, and Yoshihara argues that it is the wavelengths which are important rather than the peak shapes.

5. Inazo Nitobe (1862-1933) was a Japanese author and educator. His book Bushido: The Soul of Japan (1899) described that the Bushido (literally "the way of the warrior") had been a moral code for the Japanese. Probably, Yoshihara referred to Nitobe because Kimura's homeland was near to Nitobe's, and he guessed that Kimura would have been familiar with the ideas which Nitobe described.

Acknowledgements We would first like to express our deep appreciation to H. K. Yoshihara for giving Y. H. the primary documents of evidence on Ogawa he has collected over the years. Y. H. also acknowledges Ogawa's grandchildren for providing additional information. Some of the important resources were provided by the Tohoku University Archive of Ogawa's collections. We are thankful to E. Scerri to encourage us to include the translation of Yoshihara's paper as an appendix. We are grateful to K. Tamao and the members of the study group on the history of the discoveries of elements for advice and encouragement. Y. H. is grateful to T. Omori for advice. Y. M. acknowledges K. Obata for his technical support. We have been motivated by E. Scerri and H. En'yo for pointing out important issues concerning Ogawa's discovery.

Open Access This article is licensed under a Creative Commons Attribution 4.0 International License, which permits use, sharing, adaptation, distribution and reproduction in any medium or format, as long as you give appropriate credit to the original author(s) and the source, provide a link to the Creative Commons licence, and indicate if changes were made. The images or other third party material in this article are included in the article's Creative Commons licence, unless indicated otherwise in a credit line to the material. If material is not included in the article's Creative Commons licence and your intended use is not permitted by statutory regulation or exceeds the permitted use, you will need to obtain permission directly from the copyright holder. To view a copy of this licence, visit http://creativecommons.org/licenses/by/4.0/.

\section{References}

Aoyama, S.: Late Professor Masataka Ogawa. J. Chem. Soc. Jpn. 51, I-IV (1930). (in Japanese)

Aoyama, S., Fukuroi, T.: On the absorption spectrum of X-rays (I). Sci. Papers Phys. Chem. Inst. 12, 470473 (1933a). (in Japanese)

Aoyama, S., Fukuroi, T.: On the absorption spectrum of X-rays (III). Sci. Papers Phys. Chem. Inst. 12, 476-484 (1933b). (in Japanese)

Aoyama, S., Kimura, K., Nishina, Y.: Die Abhängigkeit der Röntgenabsorptionsspektren von der chemischen Bindung. Z. Phys. 44, 810-833 (1927). (in German)

Büchner, E.H.: The composition of thorianite, and the relative radio-activity of its constituents. Proc. R. Soc. Lond. A. 78, 385-391 (1906)

Coster, D., Hevesy, G.: On the missing element of atomic number 72. Nature 111, 79 (1923a)

Coster, D., Hevesy, G.: On the new element Hafnium. Nature 111, 182 (1923b)

Dauvillier, A.: Sur les séries L du lutécium et de l'ytterbium et sur l'identification du celtium avec l'élément de nombre atomique 72. Compt. Rend. 174, 1347-1349 (1922). (in French)

Deslattes, R.D., Kessler Jr., E.G., Indelicato, P., de Billy, L., Lindroth, E., Anton, J., Coursey, J.S., Schwab, D.J., Chang, C., Sukumar, R., Olsen, K., Dragoset, R.A.: X-ray Transition Energies (version 1.2). National Institute of Standards and Technology (2005). http://physics.nist.gov/XrayTrans

Druce, J.G.F.: Rhenium: Dvi-Manganese, The Element of Atomic Number 75. Cambridge University Press, New York (1948)

Dunstan, W.R., Blake, G.S.: Thorianite, a new mineral from ceylon. Proc. R. Soc. Lond. A. 76, $253-265$ (1905) 
Emsley, J.: Nature's Building Blocks: An A-Z Guide to the Elements, New Edition. Oxford University Press, New York (2011)

Evans, C. de B.: Traces of a new tin-group element in thorianite. J. Chem. Soc. Trans. 93, 666-668 (1908)

Fontani, M., Costa, M., Orna, M.V.: The Lost Elements: The Periodic Table's Shadow Side. Oxford University Press, New York (2015)

Goldschmidt, V.M., Muir, A. (eds.): Geochemistry. Clarendon Press, Oxford (1954)

Goto, M., Ishii, A., Ishii, D.: Measurement of relative XRF intensity of each element in energy dispersion $\mathrm{XRF}$ analysis and its application to quantitative analysis of elements. Bunseki Kagaku 36, 842-850 (1987). (in Japanese)

Gray, T.: The Elements. Black Dog \& Leventhal Publishers, Inc., New York (2009)

Haga, T.: Biography of Dr. Divers. J. Chem. Soc. Tokyo 33, 1-26 (1912). (in Japanese)

Hahn, O.: A new radio-active element, which evolves thorium emanation. Preliminary communication. Proc. R. Soc. Lond. A. 76, 115-117 (1905)

Harris, J.A., Yntema, L.F., Hopkins, B.S.: Observations on the rare earths XXIII. Element No. 61 Part Two. X-ray analysis. J. Am. Chem. Soc. 48, 1594-1598 (1926)

Hevesy, G. de: Recherches sur les Propriétés du Hafnium. Kgl. Danske Videnskab. Selskab. Mat-fys. Medd. 6, no. 7 (1925) (in French)

Imperial Cabinet of Japan: Records on Ratification of Decorations. The Year of Showa 5. Decorations Volume 2. Domestic 2: On awarding the Medal to the late Masataka Ogawa, Professor Emeritus of Tohoku Imperial University (1930). https://www.digital.archives.go.jp/item/2847700. (in Japanese)

Kahoku Shimpō Newspaper: A pursuit of Western philosophy. Article on June 1 (1919a) (in Japanese)

Kahoku Shimpō Newspaper: Comment by President Ogawa, who became the victim of autonomy due to the intention of the university that they are tired of the presidents appointed by the government. Article on June 22 (1919b) (in Japanese)

Kahoku Shimpō Newspaper: President Ogawa's research on Nipponium. Article on February 28 (1925a) (in Japanese)

Kahoku Shimpō Newspaper: Dr. Ogawa's Nipponium, will the results be announced at the end of this month? Article on March 31 (1925b) (in Japanese)

Kahoku Shimpō Newspaper: President Ogawa, who has started the establishment of the Faculty of Agriculture along with Nipponium Research. Article on September 12 (1927) (in Japanese)

Kaji, M.: Chemical Classification and the Response to the Periodic Law of Elements in Japan in the Nineteenth and Early Twentieth Centuries. In: Kaji, M., Kragh, H., Palló, G. (eds.) Early Responses to the Periodic System. Oxford University Press, New York (2015)

Kato, T.: Sights and monuments XI: Ogawa memorial garden. On-Campus Newslett. Tohoku Univ. 138, 2-3 (1990). (in Japanese)

Kikuchi, Y.: Joji Sakurai and his connections with British chemists. J. Jpn. Soc. Hist. Chem. (KAGAKUSHI) 31, 239-267 (2004). (in Japanese)

Kobayashi, M.: On the composition of thorianite. J. Chem. Soc. Tokyo 33, 549-556 (1912a). (in Japanese)

Kobayashi, M.: On the composition of thorianite. Sci. Rep. Tohoku Imp. Univ. 1, 201-206 (1912b)

Loring, F.H.: The atomic weights as mathematical functions. Chem. News 100, 281-287 (1909)

Majima, T.: Impressions on the travel in Western countries. Memoirs Alma Mater Tohoku Chem. Dept. 2, 1-7 (1925). (in Japanese)

Majima, T.: Recollections of my life (II). J. Jpn. Chem. (Kagaku no Ryoiki) 8, 137-146 (1954). (in Japanese)

Makita, S.: The new element is in it! Memoirs of Alma Mater of Tohoku Chemistry Department 8, 27-28 (1930). (in Japanese)

Marshall, H.: Inorganic chemistry. Ann. Rep. Prog. Chem. 1908, 31-72 (1909)

Meggers, W.F.: The optical spectra of rhenium. Phys. Rev. 37, 219-220 (1931a)

Meggers, W.F.: The arc spectrum of rhenium. Bur. Stand. J. Res. 6, 1027-1050 (1931b)

Moore, R.B.: Sir William Ramsay. J. Franklin Inst. 186, 29-55 (1918)

Morita, K., Morimoto, K., Kaji, D., Akiyama, T., Goto, S., Haba, H., Ideguchi, E., Kanungo, R., Katori, K., Koura, H., Kudo, H., Ohnishi, T., Ozawa, A., Suda, T., Sueki, K., Xu, H.-S., Yamaguchi, T., Yoneda, A., Yoshida, A., Zhao, Y.-L.: Experiment on the synthesis of element 113 in the reaction ${ }^{209} \mathrm{Bi}\left({ }^{70} \mathrm{Zn}\right.$, n) ${ }^{278} 113$. J. Phys. Soc. Jpn. 73, 2593-2596 (2004)

Noddack, W., Tacke, I., Berg, O.: Die Ekamangane. Naturwiss. 26, 567-574 (1925)

Ogawa, E.: Miscellaneous. Memoirs of Alma Mater of Tohoku Chemistry Department 10, $32-35$ (1932a). (in Japanese)

Ogawa, E.: Vapour pressure of rhenium heptoxide, vapour pressure and dissociation pressure of rhenium octoxide. Bull. Chem. Soc. Jpn. 7, 265-273 (1932b) 
Ogawa, M.: Letters: a letter from Mr. Masataka Ogawa. J. Chem. Soc. Tokyo 25, 542-543 (1904). (in Japanese)

Ogawa, M.: Catalogue of the joint academic exhibition of the three academic societies. J. Chem. Soc. Tokyo 28, 496-500 (1907). (in Japanese)

Ogawa, M.: Preliminary Note on a New Element in Thorianite. J. Coll. Sci. Imp. Univ. Tokyo 25, Art. 15, 1-11 (1908a) (reprinted in Chem. News 98, 249-251 (1908))

Ogawa, M.: Preliminary Note on a New Element allied to Molybdenum. J. Coll. Sci. Imp. Univ. Tokyo 25, Art. 16, 1-13 (1908b) (reprinted in Chem. News 98, 261-264 (1908))

Ogawa, M.: On new elements in thorianite. J. Chem. Soc. Tokyo 30, 1277-1299 (1909). (in Japanese)

Ogawa, M.: Lecture article: on a mineral that coexists with thorianite. J. Chem. Soc. Tokyo 32, 423 (1911). (in Japanese)

Ogawa, M.: Lecture article: recent research of Sir William Ramsay. Syoshikai Magazine 93, 84-93 (1912). (in Japanese)

Ogawa, M.: Lecture article: topics related to nipponium research. J. Chem. Soc. Tokyo 38, 396-397 (1917). (in Japanese)

Onishi, H.: Was nipponium rhenium? Chem. Chem. Ind. (Kagaku to Kogyo) 43, 1717 (1990). (in Japanese)

Onishi, H.: A discussion on Ogawa's discovery of nipponium in thorianite. J. Jpn. Soc. Hist. Chem. (KAGAKUSHI) 36, 77-78 (2009). (in Japanese)

Ono, H.: A sketch of Dr. Ogawa's humanity. Memoirs of Alma Mater of Tohoku Chemistry Department 8, 17-27 (1930). (in Japanese)

Otsuka, T.: Episodes in Academia: Tohoku Imperial University. Senshin-Sha, Tokyo (1931). (in Japanese)

Perrier, C., Segré, E.: Some chemical properties of element 43. J. Chem. Phys. 5, 712-716 (1937)

Ramsay, W.: A new mineral from ceylon. Nature 69, 533-534 (1904)

Royal Society of Chemistry: Periodic Table. https://www.rsc.org/periodic-table/element/75/rhenium. Accessed 27 May 2021

Scerri, E.: A Tale of Seven Elements. Oxford University Press, New York (2013)

Shibata, Y.: On Unknown Elements 43, 75, and 61. Oriental Magazine of Arts and Science (Toyo Gakugei Zasshi) 509, 2-7 (1925). (in Japanese)

Shibata, Z.: A tale on nipponium. Sci. Pict. (Kagaku Gaho) 29(10), 24-27 (1940). (in Japanese)

Shinoda, S.: Title of presentation: detection of Rhenium in Molybdenite in Japan. J. Chem. Soc. Jpn. 51, 460 (1930). (in Japanese)

Stintzing, H.: Eine neue Anordnung des periodischen Systems der Elemente. Z. Phys. Chem. 91U, 500-507 (1916). (in German)

Thompson, A., Attwood, D., Gullikson, E., Howells, M., Kim, K.-J., Kirz, J., Kortright, J., Lindau, I., Liu, Y., Pianetta, P., Robinson, A., Scofield, J., Underwood, J., Williams, G., Winick, H.: Center for X-ray Optics and Advanced Light Source, X-ray Data Booklet. Lawrence Berkeley National Laboratory (2009). https://xdb.lbl. gov/

Trifonov, D.N., Trifonov, V.D.: Chemical Elements: How They were Discovered. MIR Publishers, Moscow (1982)

Van der Krogt, P.: Elementymology \& Elements Multidict. https://elements.vanderkrogt.net/element.php? sym=Re (2010). Accessed 27 May 2021

Van Spronsen, J.W.: The Periodic System of Chemical Elements. Elsevier, Amsterdam (1969)

Yomiuri Shimbun Newspaper: Person of Knowledge and Affection: Condolence to Dr. Divers. Article on May 12 (1912) (in Japanese)

Yoshihara, K.: Technetium, Tohoku University, and the dawn of inorganic chemistry in Japan. On-Campus Newsletter of Tohoku University 153, 22-25 (1992). (in Japanese)

Yoshihara, H.K.: Nipponium, the element ascribable to rhenium from the modern chemical viewpoint. Radiochim. Acta 77, 9-13 (1997)

Yoshihara, K.: Nipponium: A story of the new element discovered by a Japanese. Isotope News 545, 26-29 (1999). (in Japanese)

Yoshihara, H.K.: Ogawa's discovery of nipponium and Its re-evaluation. Hist. Scientiarum 9, 257-269 (2000)

Yoshihara, K.: Masataka Ogawa and his students at Tohoku Imperial University: research of platinum group elements and X-ray spectroscopy. J. Jpn. Soc. Hist. Chem. (KAGAKUSHI) 30, 69-83 (2003). (in Japanese)

Yoshihara, H.K.: Discovery of a new element 'nipponium': re-evaluation of pioneering works of Masataka Ogawa and his son Eijiro Ogawa. Spectrochim. Acta B 59, 1305-1310 (2004)

Yoshihara, H.K.: Nipponium as a new element $(Z=75)$ separated by the Japanese chemist, Masataka Ogawa: a scientific and science historical re-evaluation. Proc. Jpn. Acad. B 84, 232-245 (2008) 
Yoshihara, K.: On the Nipponium: revisiting Eric Scerri’s View. J. Jpn. Soc. Hist. Chem. (KAGAKUSHI) 42, 206-209 (2015). (in Japanese)

Yoshihara, H.K., Nakai, I., Terada, Y., Kaji, M.: Studies of Nipponium by Masataka Ogawa and His Son Eijiro. J. Jpn. Soc. Hist. Chem. (KAGAKUSHI) 29, 209-221 (2002). (in Japanese)

Yoshihara, H.K., Kobayashi, T., Kaji, M.: Ogawa family and their 'nipponium' research: successful separation of the element 75 before its discovery by Noddacks. Hist. Scientiarum 15, 177-190 (2005)

Zainshi (Okuno, H.): Atomic numbers and undiscovered elements: "Discovery of Nipponium." Chem. Today (Gendai Kagaku) 31, 58-67 (1973). (in Japanese)

Publisher's Note Springer Nature remains neutral with regard to jurisdictional claims in published maps and institutional affiliations. 